\title{
VARIAÇÃO DA ACIDEZ DO SOLO EM RESPOSTA À ADIÇÃO DE MATERIAIS ORGÂNICOS
}

\author{
TADEU CAVAlCANTE REIS \\ Engenheiro Agrônomo
}

Orientador: Prof. Dr. ARNALDO ANTÔNIO RODELLA

Dissertação apresentada a Escola Superior de Agricultura "Luiz de Queiroz", Universidade de São Paulo, para obtenção do título de Mestre em Agronomia, Área de Concentração: Solos e Nutrição de Plantas

PIRACICABA

Estado de São Paulo - Brasil

Dezembro de 1998 


\section{ERRATA}

Pág. Parág.

Onde se lê

Leia-se

21 ...como objetivo de relacionar...

...como objetivo relacionar...

$19 \quad 1 \quad$...subamostras de esterco ...

...subamostras de: esterco ...

$213 \ldots$ de matéria orgânica, com...

...de matéria orgânica mais a testemunha, com

233 ...pelo teste de Tukey.

...pelo teste de Tukey, quando pertinente.

$28 \quad$ Fig. 1
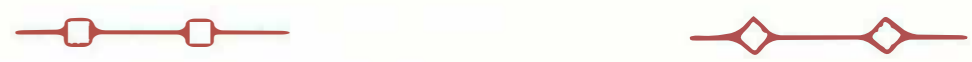

$28 \quad$ Fig. 1

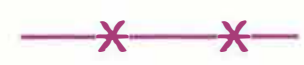

292 ...queda mais acentuada e $\mathrm{pH} .$.

...queda mais acentuada do $\mathrm{pH}$...

312 ... lodo 1 ter sido muito maior... ... lodo 1 ter sido maior...

321 ...devido a maior acidez do $\mathrm{Cb} \ldots$ ...devido ao maior poder tampão do $\mathrm{Cb} \ldots$

$38 \quad 1 \quad$...alumínio trocável do LV...

...alumínio trocável do LV, medido espectrometria...

39 Tab. 7 ... redução do $\mathrm{Al} \ldots$

... alteração do $\mathrm{Al} \ldots$

392 ...material como turfa e lodos... ...materiais como os lodos...

42 Tab. 8 ...cinética de primeiro grau... ...cinética de primeira ordem... 
Dados Internacionais de Catalogação na Publicação (CIP) DIVISÃO DE BIBLIOTECA E DOCUMENTAÇÃO - Campus "Luiz de Queiroz"/USP

Reis, Tadeu Cavalcante

Variaçāo da acidez do solo em resposta à adição de materiais orgânicos / Tadeu Cavalcante Reis. - - Piracicaba, 1998.

$65 \mathrm{p}$.

Dissertação (mestrado) - Escoia Superior de Agricultura Luiz de Queiroz, 1998. Bibliografia.

1. Acidez do solo 2. Aluminio 3. Carbono orgánico 4. Matéria orgânica do solo 5. Microbiologia do solo 6. pH do solo 7. Química do solo 1. Título

CDD 631.42 


\section{OFERECO}

À minha mãe Alzenira, pela extrema dedicação e apoio em todos os meus dias.

A minha companheira Cristina, pela compreensão e incentivo.

À minha querida irmã Maria Goretti, (In memorian)

\section{DEDICO}




\section{AGRADECIMENTOS}

Ao Professor Dr. Arnaldo Antonio Rodella, pela sua orientação dedicada, pela confiança, pela amizade e pelo exemplo.

Aos colegas Fábio Prata e Adriana M. M. Pires, pelo auxilio na execução deste trabalho e pelo apoio de verdadeiros irmãos nos momentos dificeis.

Ao Professor Dr. Jorge Antonio Gonzaga Santos, pela iniciação na pesquisa cientifica e por sempre acreditar no meu potencial.

À Secretária Maria Angélica Poletto Bernardino pela sua presteza e eficiência na resolução de problemas burocráticos.

A todos os colegas de pós-graduação, pelos bons momentos que me proporcionaram.

A CAPES, pela bolsa concedida.

Ao Estagiário Chrístian G. Rodrigues pala ajuda na realização das análises químicas.

A Laboratorista Rita de Cássia C. L. Castro pelo auxílio com as técnicas laboratoriais.

Ao corpo de professores e funcionários do Setor de Química Analítica, Departamento de Química - ESALQ/USP, pela amizade que sempre me dedicaram.

Ao Deus Pai Todo Poderoso, por ter iluminado o meu caminho e nunca ter deixado nada me faltar. 


\section{SUMÁRIO}

Página

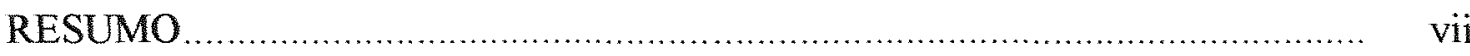

SUMMARY

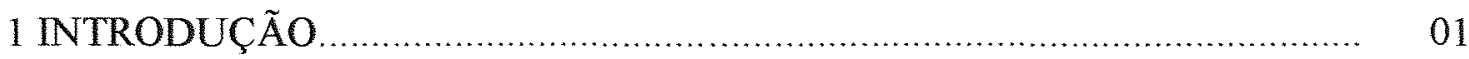

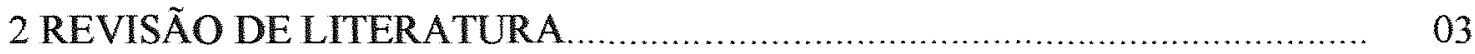

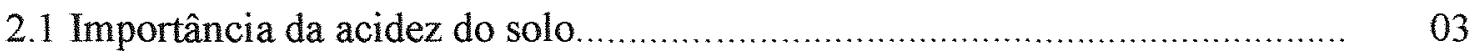

2.2 Origem da acidez do solo............................................................ 04

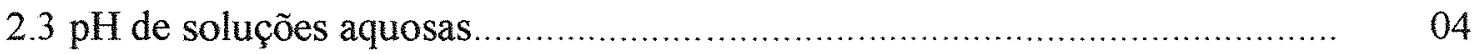

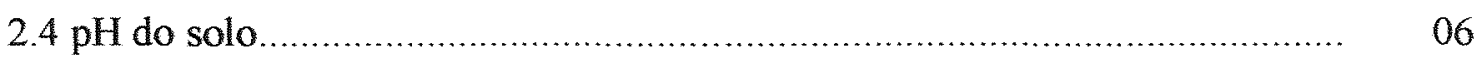

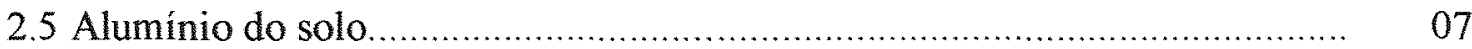

2.6 Relação entre acidez do solo e matéria orgânica...................................... 09

2.7 Decomposição dos materiais orgânicos no solo .................................. 13

2.8 Cinética de degradação .................................................................. 15

2.90 modelo de cinética de primeira ordem .......................................... 16

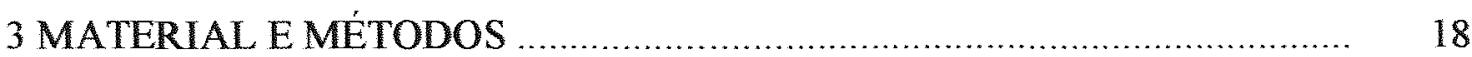

3.1 Caracterização dos solos utilizados............................................... 18

3.2 Caracterização dos materiais orgânicos utilizados......................................... 19

3.3 Experimento 1 - Efeito da adição de material orgânico sobre o pH e teor de alumínio trocável do solo ............................................................ 21

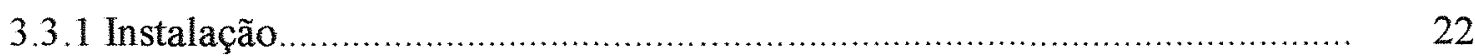

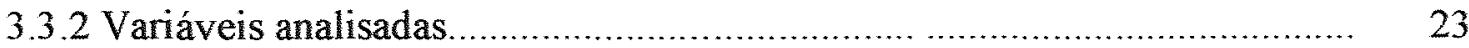

3.4 Experimento 2 - Relação entre a degradação microbiana da matéria orgânica

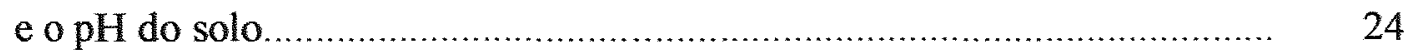

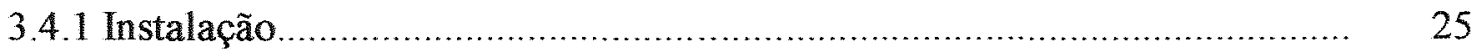




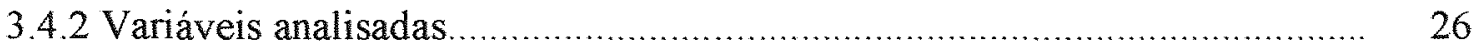

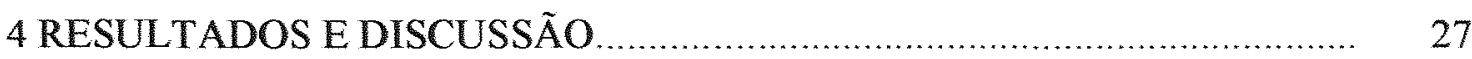

4.1 Experimento 1 - Efeito da adição de material orgânico sobre o pH e teor de alumínio trocável do solo.

4.2 Experimento 2 - Relação entre a degradação microbiana da matéria orgânica e o pH do solo 40

4.2.1 Cinética da degradação dos materiais orgânicos $\quad 40$

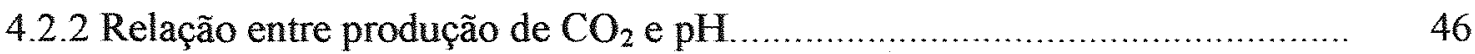

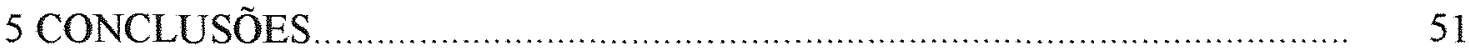

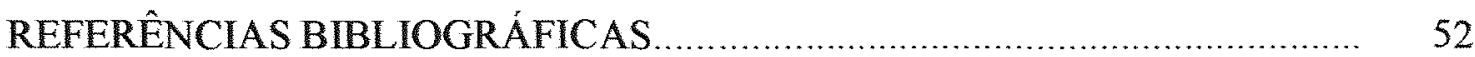

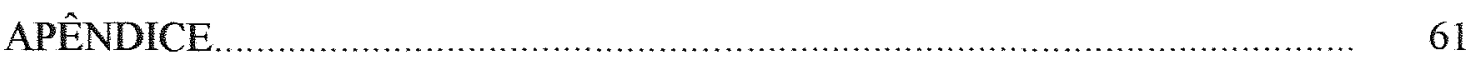




\title{
VARIAÇ̃̃O DA ACIDEZ DO SOLO EM RESPOSTA À ADIÇÃO DE MATERIAIS ORGÂNICOS
}

\author{
Autor: TADEU CAVALCANTE REIS \\ Orientador: Prof. Dr. ARNALDO ANTONIO RODELLA
}

\section{RESUMO}

Foram conduzidos dois experimentos de incubação de amostras de terra com diferentes fontes de carbono orgânico, objetivando relacionar as possíveis variações de $\mathrm{pH}$ e de alumínio trocável com a natureza dos materiais orgânicos utilizados, com as variações das formas de alumínio e com a atividade microbiológica do solo.

O primeiro estudo foi conduzido em casa de vegetação, utilizando o delineamento estatístico inteiramente casualizado em arranjo fatorial, incubando-se amostras de terra de dois solos com diferentes valores de $\mathrm{pH}$ e alumínio trocável por um periodo de 175 dias, com dez materiais orgânicos: palha da cana, feijão de porco (Canavalia ensiformis D.C.), esterco bovino e de galinha, composto orgânico, vermicomposto, turfa, vinhaça e dois lodos de esgoto com diferentes períodos de armazenamento.

Durante a incubação foram realizadas determinações periódicas de $\mathrm{pH}\left(\mathrm{H}_{2} \mathrm{O}\right.$ e $\mathrm{CaCl}_{2} 0,01 \mathrm{~mol} \mathrm{~L}^{-1}$ ) e alumínio trocável, as quais permitiram verificar que os materiais orgânicos estudados, com exceção da turfa e do composto orgânico, atuaram na redução da acidez das amostras de terra. $\mathrm{O}$ aumento do $\mathrm{pH}$ e a redução do alumínio trocável notados no estudo foram basicamente atribuidos à alcalinidade prontamente reativa de 
alguns materiais e à ação alcalinizante ou complexante de compostos liberados durante a degradação da matéria orgânica.

Além de diminuir a amplitude das variações totais de $\mathrm{pH}$ e alumínio trocável dos tratamentos, a incubação dos materiais orgânicos, nas amostras de terra de maior acidez, resultou numa alteração mais lenta deste atributo, que foi atribuída a maior dificuldade de decomposição dos materiais nessa condição.

A determinação do alumínio complexado pela matéria orgânica, através de extração com $\mathrm{CuCl}_{2}$, evidenciou que o processo de complexação contribuiu pouco com a redução do alumínio trocável do solo, ficando evidente que o aumento do $\mathrm{pH}$ foi o principal responsável pela alteração.

O segundo ensaio foi conduzido em câmaras de incubação com temperatura controlada, onde amostras de terra de um Cambissolo foram incubadas com cinco materiais orgânicos sob temperaturas de 20 e $30^{\circ} \mathrm{C}$, por um período de 38 dias. Após este período, as temperaturas foram elevadas a $35^{\circ} \mathrm{C}$ e mantidas até o final do ensaio, 71 dias. Os materiais utilizados foram: feijão de porco, esterco bovino, vinhaça, turfa e um lodo de tratamento biológico de efluentes.

Ao longo de todo o período de incubação foi realizado o acompanhamento do $\mathrm{CO}_{2}$ desprendido de cada tratamento e dos respectivos valores de $\mathrm{pH}$, determinando-se ao final dos 38 dias de incubação os teores de alumínio trocável. Os resultados indicaram que a vinhaça foi o material que apresentou maior porcentagem de mineralização, seguido do feijão de porco, esterco bovino, lodo e turfa.

Aos dados de produção de $\mathrm{CO}_{2}$ foi ajustado o modelo de cinética de primeira ordem, que permitiu o cálculo das constantes de velocidade de degradação dos materiais orgânicos.

As determinações de $\mathrm{pH}$ do solo, ao longo do período de incubação permitiram a observação de comportamentos semelhantes aos obtidos no primeiro ensaio para esse atributo, sendo que as alterações de $\mathrm{pH}$ resultantes da adição de vinhaça foram mais expressivas a $30^{\circ} \mathrm{C}$ que a $20^{\circ} \mathrm{C}$ e foram relacionadas à quantidade acumulada de $\mathrm{CO}_{2}$ liberado. 


\title{
SOIL ACIDITY ALTERATIONS IN RESPONSE TO ORGANIC MATTER ADDITIONS
}

\author{
Author: TADEU CAVALCANTE REIS \\ Adviser: Prof. Dr. ARNALDO ANTONIO RODELLA
}

\section{SUMMARY}

The effect of decomposition of organic materials on soil $\mathrm{pH}$ and exchangeable aluminum (EA) content was studied in two pot experiments.

The first experiment included two soils with low and high $\mathrm{pH}$. Ten different organic materials were incorporated and incubated with $2 \mathrm{~kg}$ of soil (during 175 days). The organic amendments included sugarcane trash, cattle manure, chicken manure, compost, worm compost, peat, sugarcane fermentation residue (SFR), two sewage sludges and a green manure (Canavalia ensiformis D.C.).

During the incubation period, soil samples were collected for $\mathrm{pH}\left(\mathrm{CaCl}_{2} 0.01\right.$ mol $\mathrm{L}^{-1}$ ) and EA determinations. Organic materials, with the exceptions of peat and compost, caused an elevation of soil $\mathrm{pH}$ and a drop in EA. Those effects were attributed both to basic compounds already present in the organic materials, as well as products of organic matter degradation. Changes in $\mathrm{pH}$ and $\mathrm{EA}$ due to the addition of organic materials were limited in the soil with low $\mathrm{pH}$, indicating a buffering effect. 
Soil was also extracted with $\mathrm{CuCl}_{2}$ in order to explain the observed changes in aluminum under the addition of organic materials. EA decreased due to $\mathrm{pH}$ elevation rather than $\mathrm{Al}$ complexation by organic compounds.

The second experiment was carried out under various temperatures, using a precision incubator set to measure BOD (Biochemical Oxygen Demand). Five organic materials (cattle manure, SFR, sewage sludge and green manure) were incubated at 20 or $30^{\circ} \mathrm{C}$ for 38 days. After-wards the temperature was raised to $35^{\circ} \mathrm{C}$ and the incubation then continued for 43 days. Soil incubation was carried out in closed jars in order to measure soil respirometry $\left(\mathrm{CO}_{2}\right.$ production). Soils samples for $\mathrm{pH}\left(\mathrm{CaCl}_{2}\right)$ determinations were also collected. Total $\mathrm{CO}_{2}$ evolved was quantified by a conductimetric method, and this data was fitted to a first order kinetics model.

First-order rate constants were successfully used to monitor the process of degradation. However, for sewage sludge a time independent constant was added to first order model to account for the instantaneous productions of $\mathrm{CO}_{2}$, which was detected at both temperatures. The amount of $\mathrm{CO}_{2}$ produced at the beginning of the incubation was attributed to the reaction between carbonate and soil acid. During the processing of sludge, calcium oxide is added for $\mathrm{pH}$ adjustment, and this compound is transformed into $\mathrm{CaCO}_{3}$ after it reacts with $\mathrm{CO}_{2}$ from the atmosphere. This result indicated that respirometry data from sludge incubation may be affected by $\mathrm{CO}_{2}$ production of from inorganic sources.

Respirometry from SFR fit well with first-order kinetic model. During the early periods of incubation, the amounts of $\mathrm{CO}_{2}$ produced after the addition of SFR were smaller than those produced in soil from the control (no organic material added).

The highest \% carbon mineralized and the highest first-order rate constants were observed for SFR. The amounts of $\mathrm{CO}_{2}$ produced during incubation of SFR were well correlated to changes in soil $\mathrm{pH}$. 


\section{INTRODUCÃO}

A matéria orgânica aplicada ao solo exerce grande influência sobre suas propriedades químicas, físicas e biológicas. Após incorporação de materiais orgânicos ao solo, uma parte do carbono adicionado é emanado $\mathrm{como}^{\mathrm{CO}_{2}}$ e o restante pode permanecer inalterado ou ser incorporado à biomassa microbiana. Esse processo de transformação da matéria orgânica é vital para o funcionamento dos ecossistemas terrestres associados à atividade humana.

Nos solos onde fontes de carbono orgânico são incorporadas, dentre outras alterações, ocorre nítida variação em sua reação, expressa pelo $\mathrm{pH}$ e pela concentração de alumínio trocável, afetando diretamente sua fertilidade.

No Brasil, a maioria dos solos apresentam média a alta acidez, o que resulta em niveis tóxicos de alumínio e deficiência de nutrientes às plantas. A incorporação de matéria orgânica na forma de adubação verde, restos de culturas, estercos, resíduos agroindustriais de natureza orgânica, lodo de tratamento biológico de efluentes, entre outros, é prática frequentemente recomendada para solos com baixo teor de carbono orgânico visando obter uma série de beneficios, entre os quais, a redução da acidez do solo

Embora as variações de $\mathrm{pH}$ e alumínio trocável de solos incubados com fontes de matéria orgânica sejam frequentemente abordadas, ainda podem ocorrer questionamentos na interpretação desse processo.

A hipótese relacionada ao presente trabalho é que materiais orgânicos de diferentes naturezas afetam o $\mathrm{pH}$ e o teor de alumínio trocável do solo de modos distintos, que podem ser relacionados diretamente à composição química dos materiais, natureza do solo e fatores ambientais. 
O presente trabalho teve como objetivo de relacionar as variações de $\mathrm{pH}$ e do alumínio trocável do solo, ocorridas em função da incubação de materiais orgânicos de diferentes procedências, com a natureza dos mesmos, com possiveis variações das formas de alumínio e com a atividade microbiológica do solo. 


\section{REVISÃO DE LITERA TURA}

\subsection{A importância da acidez do solo}

O desenvolvimento de culturas pode ser prejudicado em solos ácidos. Como a maioria dos solos brasileiros apresentam média a alta acidez, com pH em água normalmente menor que 5,5 (Veloso, 1992), níveis tóxicos de alumínio e manganês podem ser observados, além de deficiência de cálcio, magnésio e fósforo.

A acidez do solo também se relaciona com a retenção de cátions pelo complexo de cargas negativas do solo. Diferentemente das regiões temperadas, nos solos das regiões tropicais ocorre, em geral, predominância de cargas variáveis, dependentes dentre outros fatores do $\mathrm{pH}$, o que pode determinar, sob condições de acidez elevada, uma capacidade de troca catiônica (CTC) baixa ou até mesmo nula (Malavolta \& Kliemann, 1985).

Como efeito nocivo da acidez do solo, também pode ser observada em $\mathrm{pH}$ inferior a 5,5 uma sensivel redução da atividade microbiana, principalmente de bactérias, influenciando assim os processos biológicos do solo como mineralização, nitrificação e fixação de nitrogênio (Fassbender, 1975). 


\subsection{Origem da acidez do solo}

Várias são as causas da acidez do solo. Malavolta (1985) as atribui à: percolação das cátions básicos e consequente acúmulo de $\mathrm{H}_{3} \mathrm{O}^{+}$; a decomposição dos minerais de argila e o aparecimento de $\mathrm{Al}$ trocável; oxidação microbiana do nitrogênio amoniacal; exudação de íns $\mathrm{H}^{+}$pelas raizes das plantas para a manutenção do equilibrio eletrostático interno, após a absorção de cátions e dissociação de radicais carboxílicos e fenólicos da matéria orgânica.

Segundo Melo (1985), o alumínio surge no solo, na forma trocável e na solução, devido ao processo de dissolução de hidróxido de alumínio amorfo e cristalino em meio acido. Com a formação dos monômeros alumínio, este elemento torna-se responsável por grande parte da acidez do solo pois, quando em solução na forma de íon hexahidratado, apresenta um comportamento ácido, expresso, segundo a teoria de Bronsted-Lowrys, pelos seguintes equilibrios de transferência de prótons:

$$
\begin{aligned}
& \left.\underset{\text { ácido }}{\left[\mathrm{Al}\left(\mathrm{H}_{2} \mathrm{O}\right)_{6}\right]^{3+}}+\underset{\text { base }}{\mathrm{H}_{2} \mathrm{O}} \longleftrightarrow \underset{\text { ácido }}{\mathrm{H}_{3} \mathrm{O}^{+}}+\underset{\text { base }}{\mathrm{Al}(\mathrm{OH})\left(\mathrm{H}_{2} \mathrm{O}\right)_{5}}\right]^{2+}
\end{aligned}
$$

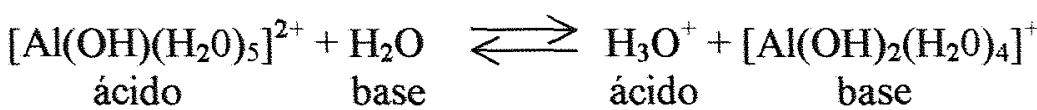

$$
\begin{aligned}
& {\left[\mathrm{Al}(\mathrm{OH})\left(\mathrm{H}_{2} \mathrm{O}\right)_{4}\right]^{+}+\mathrm{H}_{2} \mathrm{O} \rightleftarrows \mathrm{H}_{3} \mathrm{O}^{+}+\mathrm{Al}(\mathrm{OH})_{3} 3 \mathrm{H}_{2} \mathrm{O}} \\
& \text { ácido base ácido base }
\end{aligned}
$$

\section{$2.3 \mathrm{pH}$ de soluções aquosas}

$\mathrm{O}$ conceito de $\mathrm{pH}$ deriva do equilíbrio de ionização das moléculas de água, definido por um parâmetro denominado constante do produto iônico da água. Pela definição original de Sorensen, $\mathrm{pH}$, que significa potencial de hidrogênio, corresponde ao valor negativo do logaritmo da concentração de ions hidrogênio presentes em uma solução, podendo variar entre 0 e 14. Em vista do exposto, fica evidente que o pH é um parâmetro de soluções aquosas, embora seja por vezes empregado para meios não aquosos. 
Com o desenvolvimento do conceito termodinâmico de atividade, a definição de $\mathrm{pH}$ foi alterada para valor negativo do logaritmo da atividade de íons hidrogênio. $\dot{\mathrm{E}}$ interessante constatar que um conceito tão utilizado seja definido em termos de um atributo que, em princípio, é imensurável, pois a atividade do íon hidrogênio, como de qualquer outra espécie iônica isolada, não pode ser medida diretamente pelo fato de que um íon não pode ocorrer em uma solução sem que ocorra outro de carga oposta. Entretanto, é possivel medir uma quantidade que, se não é exatamente igual à atividade do íon hidrogênio, é muito próxima a ela.

Modernamente, definições de pH são estabelecidas em termos operacionais e não termodinâmicos, pela medida de potencial de eletrodo de hidrogênio de soluções padrão. Nas medidas usuais de pH o eletrodo mais empregado é o de vidro (Bates, 1973). Essas escalas operacionais são estabelecidas com base na equação de Nernst, que resulta na expressão:

$$
\mathrm{pH}(\text { amostra })=\mathrm{pH}(\text { solução padrão })+\left(\mathrm{E}_{\mathrm{a}}-\mathrm{E}_{\mathrm{p}}\right) \mathrm{F} / 2,303 \mathrm{RT}
$$

na qual, $E_{a}$ e $E_{p}$ são os potenciais do eletrodo de vidro nas soluções de amostra e padrão, respectivamente; $\mathrm{F}$ é a constante de Faraday; $\mathrm{R}$ a constante dos gases perfeitos e $\mathrm{T}$ a temperatura em graus Kelvin. À temperatura de $25^{\circ} \mathrm{C}$ e para potenciais de eletrodo medidos em milivolts tem-se:

$$
\mathrm{pH}(\text { amostra })=\mathrm{pH}(\text { solução padrão })+\left(\mathrm{E}_{\mathrm{a}}-\mathrm{E}_{\mathrm{p}}\right) / 59,15
$$

Das nove soluções padrão disponíveis, cinco são aceitas pela IUPAC International Union of Pure and Applied Chemistry- para definição operacional da escala de $\mathrm{pH}$, e destas, duas são rotineiramente empregadas na aferição de equipamentos para determinação de $\mathrm{pH}$ de soluções:

pH 6,865 a $25^{\circ} \mathrm{C}$ : solução $0,025 \mathrm{~mol} \mathrm{~kg}^{-1}$ em $\mathrm{KH}_{2} \mathrm{PO}_{4}$ e $0,025 \mathrm{~mol} \mathrm{~kg}^{-1} \mathrm{Na}_{2} \mathrm{HPO}_{4}$ pH 4,008 a $25^{\circ} \mathrm{C}$ : solução $0,05 \mathrm{~mol} \mathrm{~kg}^{-1}$ de ftalato ácido de potássio 
Essas soluções são empregadas para aferir o medidor de $\mathrm{pH}$ pelo chamado método de calibração de dois pontos, que se utiliza dois controles independentes para determinar um intervalo linear de calibração. Este procedimento apresenta vantagens sobre a calibração com uma única solução padrão, efetuada em antigos medidores de $\mathrm{pH}$, pois nesta é necessário a pressuposição de que o eletrodo tem resposta nernestiana, ou seja, uma relação linear entre potencial e $\mathrm{pH}$, com coeficiente angular fixo de 59,15 milivolts.

\section{$2.4 \mathrm{pH}$ do solo}

O termo $\mathrm{pH}$ do solo deve ser entendido como o pH de uma suspensão de solo em água ou solução salina. Assim, o pH do solo depende da relação entre quantidades de terra e de solução extratora, concentração de sais solúveis, tempo de extração entre outros.

A diluição resulta no aumento do $\mathrm{pH}$ da suspensão, podendo ultrapassar uma unidade de pH quando se passa da condição de pasta saturada para suspensão, com relação solo:água de 1:5 (Chapman et al., 1941). Em 1930, a relação solo:água de 1:2,5 foi adotada pelo Comitê de Reação do Solo da Sociedade Internacional de Ciência do Solo. Segundo Raij (1986), o efeito da diluição está relacionado com a variação da concentração de sais no meio. Com o aumento da concentração salina, ocorre compressão da dupla camada elétrica, o que faz com que o gradiente de concentração do ion hidrogênio através da mesma se reduza e o pH da suspensão diminua, de forma que se aproxime do $\mathrm{pH}$ da superficie das partículas. Por outro lado, o aumento da concentração do eletrólito na suspensão favorece o deslocamento de $\mathrm{Al}^{3+}$ do complexo de troca e, consequentemente, o processo de hidrólise desse íon, o qual responde por parte da diminuição do pH (Ragland \& Coleman, 1960).

Sabendo que a concentração de sais solúveis do solo podiam variar de forma sazonal, em função de adubações e de variações na precipitação pluviométrica, Scohofield \& Taylor (1955) sugeriram que leituras de $\mathrm{pH}$ fossem feitas em solução de $\mathrm{CaCl}_{2} 0,01 \mathrm{~mol} \mathrm{~L}^{-1}$, para que houvesse nivelamento do efeito dos sais sobre a medida de 
pH do solo. Segundo Peech (1965), essa condição de concentração não é muito diferente, em ordem de grandeza, daquelas existentes em soluções de solos não salinos, em condições ótimas de umidade.

Embora seja uma medida muito simples de ser efetuada, o $\mathrm{pH}$ pode informar não apenas se o solo é ácido, mas ainda indicar a disponibilidade de micronutrientes e fósforo ou a toxicidade de outros elementos. Quando o $\mathrm{pH}$ em água do solo está abaixo de 4 , indica a presença de ácidos livres, como $\mathrm{H}_{2} \mathrm{SO}_{4}$, por exemplo. Valores entre 4 e 5 indicam a presença do cátion alumínio em sua forma hidratada $\left[\mathrm{Al}\left(\mathrm{H}_{2} \mathrm{O}\right)_{6}\right]^{3+}$, com efeitos sobre o desenvolvimento radicular das plantas. Em solos com $\mathrm{pH}$ acima de $\mathrm{pH}$ 5,5 , a química do alumínio é dominada por uma complexa mistura de íons hidroxialumínio altamente polimerizados. Finalmente tem-se os solos calcáreos, com pH entre 7 a 8,3 , indicando a presença de $\mathrm{CaCO}_{3}$ (Thomas, 1996).

\subsection{Alumínio do solo}

A intensidade dos efeitos adversos ocasionados pelo alumínio na morfologia das plantas, sobretudo nas raízes, tem se mostrado altamente correlacionada com a atividade do íon $\mathrm{Al}^{3+}$ na solução do solo (Brenes \& Pearson, 1973; Pavan, 1982). Portanto, qualquer reação que o remova da forma iônica reduzirá seu efeito tóxico (Bartlett \& Riego, 1972). A matéria orgânica tem se mostrado bastante efetiva na minimização do efeito tóxico do alumínio, seja pelo mecanismo de precipitação devido ao aumento do pH (Yan, 1996) ou pela sua complexação por ácidos orgânicos de baixo peso molecular (Hue, 1986).

A fração trocável do alumínio no solo envolve principalmente as formas monoméricas deste elemento, enquanto os polímeros inorgânicos e o alumínio complexado pela matéria orgânica constituem a fração não trocável (Mc Lean, 1976).

Juo \& Kamprath (1979) definiram como "aluminio reativo do solo" o conjunto das seguintes espécies químicas: o alumínio solúvel e prontamente trocável; os polímeros positivamente carregados de hidroxialumínio de vários tamanhos e graus de hidratação; o hidroxialuminio situado nas entrecamadas de vermiculita e 
montmorilonita; íns $\mathrm{Al}^{3+}$ e íons hidroxialumínio associados a matéria orgânica e as formas amorfas mais solúveis de $\mathrm{Al}(\mathrm{OH})_{3}$. Entretanto, como destacam Pionke \& Corey (1967), não existe uma linha divisória clara entre a fração trocável e não trocável, sendo essas formas normalmente diferenciadas em função do método usado na determinação.

A solução neutra de $\mathrm{KCl} 1 \mathrm{~mol} \mathrm{~L}^{-1}$ tem sido largamente empregada na extração do alumínio trocável dos solos (Lin \& Coleman, 1960), sendo considerada um extrator eficiente nesta determinação. Segundo Pionke \& Corey (1967), a solução de acetato de amônio tamponada a pH 4,8 extrai uma fração dos polímeros inorgânicos de alumínio e o aluminio complexado pela matéria orgânica. Soluções de $\mathrm{LaCl}_{3} 0,33 \mathrm{~mol} \mathrm{~L}^{-1}$ e de $\mathrm{CuCl}_{2} 0,5 \mathrm{~mol} \mathrm{~L}^{-1}$ tem se mostrado efetivas na extração das formas trocáveis e não trocáveis de alumínio, particularmente da fração complexada pela matéria orgânica, embora possam extrair igualmente polímeros de hidroxialumínio inorgânicos (Juo \& Kamprath, 1979). A capacidade de extração da solução de $\mathrm{CuCl}_{2}$ se deve a alta afinidade do ín $\mathrm{Cu}^{2+}$ por radicais carboxilicos da matéria orgânica aos quais o ion $\mathrm{Al}^{3+}$ está associado

Miyazawa et al. (1993) quantificando a contribuição da complexação na redução dos teores de alumínio trocável do solo sob adição de matéria orgânica, avaliaram o alumínio complexado através da diferença entre o teor de $\mathrm{Al}$ extraído por $\mathrm{CuCl}_{2}$ e por $\mathrm{KCl}$. Já Mendonça (1995), estudando a relação da oxidação da matéria orgânica com as formas de $\mathrm{Al}$ no solo, considerou a diferença entre os teores do elemento extraído por $\mathrm{LaCl}_{2}$ e $\mathrm{KCl}$ como o alumínio reativo fracamente associado à matéria orgânica e a diferença entre teores extraídos por $\mathrm{CuCl}_{2}$ e $\mathrm{LaCl}_{2}$ como as formas reativas fortemente associadas às frações orgânicas e minerais.

Segundo Pavan (1983), em determinados solos, as quantidades de aluminio não trocáveis podem atingir valores bastante elevados em relação ao alumínio total extraído. Embora esta fração não exerça efeitos fitotóxicos diretos, atua no tamponamento do $\mathrm{pH}$ do solo e afeta a atividade do $\mathrm{Al}^{3+}$ na solução (Juo \& Kamprath, 1979). 


\subsection{Relação entre matéria orgânica e acidez do solo}

É conhecido o fato de que as transformações decorrentes da aplicação de matéria orgânica ao solo afetam diretamente a disponibilidade dos nutrientes às plantas, através do impacto nas propriedades químicas e biológicas do solo. Aliado a este fato, a melhoria das propriedades fisicas e físico-químicas é refletida sobre as produções das culturas.

Apesar da relação entre a matéria orgânica e a acidez do solo ser bastante estudada, diferentes pontos de vista são abordados na interpretação desse processo. $O$ efeito mais comum da adição de diferentes fontes de matéria orgânica, quase sempre é a elevação do pH do solo (Paz et al., 1976; Mello et al., 1982; Cambuim \& Cordeiro, 1986 e Camargo et al. 1987). Para se interpretar o comportamento do $\mathrm{pH}$ dos solos com a incorporação de matéria orgânica é necessário considerar as variações na composição química dos materiais orgânicos, os atributos dos solos utilizados e as condições ambientais de decomposição.

Eira \& Carvalho (1970), adicionaram diferentes fontes de carbono ao solo e verificaram que materiais mais estabilizados, ou seja, em estado mais adiantado de decomposição da fração orgânica, causaram apenas uma alteração imediata do pH do solo, enquanto os que não haviam sofrido uma prévia decomposição, além da alteração logo no início da incubação, também promoveram variações no decorrer desse processo. Isto sugere que as alterações de $\mathrm{pH}$ durante o periodo de incubação de materiais orgânicos no solo são diretamente ligadas à decomposição destes produtos. Assim, diferenciam-se duas formas de alteração do $\mathrm{pH}$ do solo pelos materiais orgânicos: uma que ocorre logo após a adição devido a alcalinidade ou acidez destes, e outra, devido a liberação de seus constituintes durante a decomposição realizada pelos microorganismos do solo. Os autores observaram que a incorporação de palha de cana e torta de algodão promoveu uma elevação do $\mathrm{pH}$ do solo. Um efeito oposto, contudo, foi detectado durante a decomposição da glucose.

Ernani \& Gianello (1983) incorporando cama de frango ao solo, atribuíram a elevação do $\mathrm{pH}$ do mesmo tanto à difusão da amônia como à passagem de cálcio e 
magnésio do material para o solo. $\mathrm{O}$ aumento no teor destes cátions é também citado por Mazur et al. (1983) para explicar o aumento do pH do solo pela adição de composto de residuos urbanos. Como os materiais orgânicos citados apresentam caráter alcalino, pode-se atribuir à esta característica a capacidade dos mesmos em aumentar o $\mathrm{pH}$ dos solos e não propriamente ao aumento da concentração de cátions como cálcio magnésio. $\mathrm{O}$ efeito isolado destes cátions não poderia explicar a elevação do $\mathrm{pH}$, visto que quando adicionados ao solo na forma de sais neutros, como $\mathrm{CaCl}_{2}$ e $\mathrm{MgCl}_{2}$ por exemplo, aumentam a força iônica da solução do solo, diminuindo assim o $\mathrm{pH}$ devido ao deslocamento de $\mathrm{Al}^{3+}$ dos sítios de adsorsão e posterior hidrólise (Takachi \& Pavan, 1995). De acordo com Korcak (1980), materiais orgânicos com elevada alcalinidade como lodos de esgoto, aumentam o pH do solo independentemente das transformações da matéria orgânica.

Essas considerações se baseiam no fato de não serem cátions, mas sim ânions, que atuando como bases de Bronsted-Lowry, neutralizam ions $\mathrm{H}^{\top}$ e elevam o $\mathrm{pH}$ do solo. Segundo Alcarde (1985), os materiais que podem ser usados na correção da acidez dos solos são aqueles que contém óxidos, hidróxidos, carbonatos e silicatos de cálcio e ou de magnésio como princípios ativos, tais como: calcário dolomítico, calcário calcinado, óxido de cálcio ou de magnésio, hidróxido de cálcio, hidróxido de magnésio entre outros.

O papel de cátions e ânions na acidez do solo foi evidenciado por Yan et al. (1996), que cultivando leguminosas em vasos contendo $5 \mathrm{~kg}$ de solo por um periodo de 45 dias, observaram uma redução do $\mathrm{pH}$ do solo de 6 para 5,64, a qual foi atribuida ao mecanismo de liberação de prótons $\left(\mathrm{H}^{+}\right)$pelas raízes. Em conseqüência dessa liberação, as plantas acumularam ânions orgânicos capazes de neutralizar ácidos do solo caso o tecido vegetal fosse adicionado ao mesmo. Os autores determinaram uma quantidade de prótons liberados de $3,27 \mathrm{cmol} \mathrm{H}^{+}$por vaso e uma quantidade aproximadamente equivalente de alcalinidade, $3,44 \mathrm{cmol}$, acumulada na parte aérea das plantas. Com o retorno da parte aérea da leguminosa ao solo, o pH aumentou de 5,64 para 6,29 após 7 dias. Conduzindo-se a incubação até 307 dias, observou-se uma nova acidificação do solo até pH 5,86 que segundo os autores, foi devido à nitrificação. 
Os resultados obtidos por Miyazawa et al. (1993), na avaliação do efeito da aplicação de vinte espécies de plantas para adubação verde e residuos de culturas sobre o $\mathrm{pH}$ e Al do solo, já haviam indicado que os resíduos de leguminosas causaram maiores acréscimos no pH, quando comparados com a aplicação de resíduos de gramíneas. Esta observação pode ser relacionada aos resultados de Pierre \& Banwart (1975), que encontraram valores médios de alcalinidade em cinzas de leguminosas e gramineas iguais a 110 e $69 \mathrm{cmol} \mathrm{kg}^{-1}$, respectivamente.

A formação de complexos entre ligantes orgânicos e o íon alumínio, sugerido por Clark \& Nichol (1966) como explicação para o maior desenvolvimento de plantas em solos que receberam matéria orgânica, foi utilizada por Hoyt \& Turner (1975) para explicar o aumento do $\mathrm{pH}$ do solo após a adição de farelo de alfafa. Estes autores justificaram a capacidade complexante da matéria orgânica do farelo de alfafa sobre o alumínio, através de comparação da curva de titulação potenciométrica de uma solução pura deste íon, com a curva de uma solução do íon contendo o material orgânico. Embora os dados apresentados no trabalho sejam bastante coerentes, pode-se argumentar que os indícios da existência de complexação de aluminio foram obtidos em testes de laboratório, sem a garantia de que o processo seria reproduzido no solo, sob os efeitos das transformações microbianas.

Rodella et al. (1983), assim como Hoyt \& Turner (1975), observaram a existência de atividade complexante da vinhaça sobre o ín alumínio de uma solução de um sal desse elemento. Verificaram ainda, que o efeito da vinhaça na redução da acidez trocável e elevação do $\mathrm{pH}$ do solo, foram dependentes da temperatura e umidade de incubação. De forma semelhante, Cang et al. ${ }^{1}$, citados por Yadvinder-Singh et al. (1992), trabalhando com adubação verde verificaram que, enquanto foram detectadas mudanças no $\mathrm{pH}$ do solo, incubado a $28^{\circ} \mathrm{C}$, elas não ocorreram a $15^{\circ} \mathrm{C}$. Essas observações provavelmente relacionam as alterações do pH no decorrer da incubação à atividade dos microrganismos do solo.

\footnotetext{
${ }^{1}$ CANG Dong-ging; WANG Jing-hua; ZHANG Xiao-nian. Acidity in tu tian-ren (ed.). Phisical Chemistry of Paddy Soils. Beijing: Science Press, p. 131-156, 1985.
} 
Procurando avaliar o efeito da vinhaça sobre a acidez de três solos, Mattiazzo \& Gloria (1987) adotaram tratamentos com e sem aplicação de brometo de metila e verificaram que nos tratamentos com vinhaça e esterilização do solo ocorreu a mesma diminuição inicial do $\mathrm{pH}$ observada no solo tratado apenas com o resíduo. Contudo, no primeiro caso o aumento deste atributo só ocorreu quando se interrompeu a aplicação de brometo de metila, evidenciando que a paralisação da atividade microbiana impediu a alteração do $\mathrm{pH}$ e, segundo os autores, a consequente diminuição da concentração de alumínio trocável. Sugeriu-se como causa para esta elevação do pH, a hipótese que a adição de vinhaça tornou o meio redutor, promovendo consumo de íons $\mathrm{H}^{+}$, justificativa esta também preconizada por Sengik et al. (1988). Este mecanismo foi parcialmente esclarecido por Leal et al. (1983), ao incubar um solo com doses crescentes de vinhaça e uma quantidade conhecida de $\mathrm{NO}_{3}^{-}$, que funcionou como um receptor de elétrons adicional ao oxigênio presente. Através das medidas de $\mathrm{CO}_{2}$ liberado, pôde-se relacionar a aplicação da vinhaça com o aumento da atividade microbiana, a qual tem como consequência a intensificação do consumo de $\mathrm{O}_{2}$ do solo. Aliada à baixa velocidade de difusão do $\mathrm{O}_{2}$ em solo úmido, a intensa respiração causou um abaixamento do potencial redox do solo, o qual foi comprovado através de medidas diretas e pela diminuição do teor de $\mathrm{NO}_{3}{ }^{-}$do solo. Sob tais condições, a disponibilidade de $\mathrm{O}_{2}$ é restrita e o substrato reduzido, tal como os compostos orgânicos da vinhaça, doa elétrons que são transferidos a receptores terminais como óxidos de nitrogênio, óxidos de ferro, óxidos de manganês, entre outros. Reações de redução, como as indicadas a seguir, envolvem consumo de ions $\mathrm{H}^{+}$com consequente elevação do $\mathrm{pH}$

$$
\begin{aligned}
& 2 \mathrm{NO}_{3}^{-}+12 \mathrm{H}^{+}+10 \mathrm{e}^{-} \rightleftarrows \mathrm{N}_{2}+6 \mathrm{H}_{2} \mathrm{O} \\
& \mathrm{Fe}(\mathrm{OH})_{3}+\mathrm{e}^{-} \rightleftarrows \mathrm{Fe}(\mathrm{OH})_{2}+\mathrm{OH}^{-}
\end{aligned}
$$

Numa revisão sobre os efeitos da adubação verde sobre as propriedades do solo, Yadvinder-Singh et al. (1992) discutiram as causas das alterações de pH com a aplicação de matéria orgânica. Se por um lado há a possibilidade de acidificação do solo pelos ácidos orgânicos e $\mathrm{CO}_{2}$ produzidos durante a decomposição, o $\mathrm{pH}$ pode ser 
elevado pela redução dos óxidos de Fe e Mn e pela alcalinidade natural do material vegetal. Dessa forma, os autores acreditam que a direção e magnitude das mudanças no pH do solo após a incorporação de adubo verde são determinadas pelo balanço entre a quantidade de prótons consumidos e liberados.

\subsection{Decomposição dos materiais orgânicos no solo}

A velocidade da decomposição dos materiais orgânicos adicionados a solos depende de uma série de fatores relacionados com a composição química e quantidade do material, e com as características físico-químicas e biológicas do solo, bem como as condições climáticas.

No trabalho de Zilbilske (1987), a alta relação $\mathrm{C} / \mathrm{N}$ do lodo de indústria de celulose aplicado ao solo, mostrou ser a principal causa da redução de liberação de $\mathrm{CO}_{2}$ pela respiração microbiana ao se aumentar a dose de $17 \mathrm{~g} \mathrm{~kg}^{-1}$ para $267 \mathrm{~g} \mathrm{~kg}^{-1}$. Pode-se concluir desta forma que materiais orgânicos de alta relação $\mathrm{C} / \mathrm{N}$, quando aplicados em altas doses, têm a sua mineralização dificultada pala insuficiência de nitrogênio.

Por outro lado, materiais orgânicos com baixa relação $\mathrm{C} / \mathrm{N}$ podem ter uma rápida e completa mineralização e muitas vezes acelerar a decomposição da matéria orgânica nativa do solo, o que se denomina "efeito primming". Isto foi mostrado no trabalho de Hernandez et al.(1988), no qual, após seis meses de incubação de um solo com cinco materiais orgânicos, foram detectados teores de carbono orgânico mais baixos que o da testemunha nas parcelas tratadas com materiais de menor relação $\mathrm{C} / \mathrm{N}$. Minhoni et al. (1990) também relacionou o nitrogênio como o fator limitante da decomposição de vinhaça, bagaço de cana e palha de milho no solo.

Outro fator determinante na decomposição dos materiais orgânicos é a temperatura. Alexander (1967) relatou que a mineralização do carbono é mais lenta a baixas temperaturas e que a elevação desta está associada com um maior desprendimento de $\mathrm{CO}_{2}$. Parr (1975) considerou a faixa de $30-35^{\circ} \mathrm{C}$ como a ideal para a máxima velocidade de decomposição de materiais orgânicos de modo geral. 
A decomposição de materiais orgânicos adicionados a solos pode ser avaliada tanto em condições de campo como de laboratório, fornecendo dados úteis para orientar o manejo daqueles produtos. Os ensaios em campo permitem fazer avaliações em escala real e em geral se baseiam em determinações de carbono do solo em diversas fases (Tester, 1990) ou medições de $\mathrm{CO}_{2}$ liberado do solo pela respiração dos microorganismos. Segundo Naganawa et al. (1989), estas determinações feitas em condição de campo estão sujeitas a interferência de diversos fatores, como variação de temperatura.

Quantificações do $\mathrm{CO}_{2}$ emanado de amostras de terra, incubadas com materiais orgânicos em laboratório dentro de respirômetros, são utilizadas para a avaliação da atividade biológica do solo, incluindo o cálculo de biomassa microbiana (Grisi, 1984; Sparling, 1992), bem como para determinação de taxas de decomposição de materiais adicionados. Estudos desta natureza permitem, num curto intervalo de tempo, a obtenção de informações seguras sobre o comportamento de materiais orgânicos no solo (Cerri et al., 1994).

Os respirômetros, geralmente empregados, se enquadram em dois tipos: fechados e dinâmicos. Em ambos, a maneira mais comum de coletar $\mathrm{o} \mathrm{CO}_{2}$ consiste na sua absorção por uma solução alcalina. Basicamente, os respirômetros fechados são simples recipientes perfeitamente vedados, de tamanhos e formas variadas, nos quais se acondicionam o solo e os materiais a serem estudados, sendo abertos periodicamente para promover a aeração e a troca da solução coletora de $\mathrm{CO}_{2}$. Em geral, derivam do sistema proposto por Bartha \& Pramer (1965) e, pelo baixo custo e facilidade de operação, são largamente utilizados (Fine et al., 1989 e Hadas \& Portnoy, 1994).

Os sistemas dinâmicos, como o proposto por Bower et al. (1958), são submetidos a um fluxo de ar isento de $\mathrm{CO}_{2}$, passando continua ou intermitentemente através dos vasos onde estão as amostras. De construção mais complexa e onerosa, este sistema foi utilizado, entre outros, por Smith \& Hadley (1990) e Cerri et al. (1994). 


\subsection{Cinética de degradação}

$\mathrm{Na}$ avaliação do comportamento da matéria orgânica no solo é importante a determinação do modelo de cinética de degradação, pois através de parâmetros numéricos como constante de velocidade, o processo pode ser relacionado a diferentes variáveis. Como exemplo, tem-se a avaliação da biodegradabilidade de materiais orgânicos potencialmente poluentes. Morrill et al. (1982) aplicaram modelos cinéticos à degradação de pesticidas no solo, apresentando as limitações de ajuste de modelos exponenciais, como o de primeira ordem, na presença do produto proveniente de aplicações anteriores.

Após o início da degradação de um composto químico, a quantidade deste diminui em função do tempo e a forma desta curva será função da natureza do composto, de sua concentração, dos organismos decompositores e de vários fatores ambientais (Alexander \& Scow, 1989). Segundo estes autores, o solo é um ambiente complexo do ponto de vista químico, físico e microbiológico, o que dificulta a extrapolação de resultados de cinética obtidos em culturas puras de microrganismos, sob condições controladas. As principais razões que contribuem para isto são: a presença de metabólitos das espécies biodegradantes, que podem reprimir ou acelerar o consumo do composto testado; a sorção das moléculas orgânicas pelas argilas ou constituintes húmicos, de modo a diferenciar a sua cinética; a diferença entre a cinética de degradação de compostos solúveis e insolúveis em água; a necessidade de um período de aclimatação que alguns compostos orgânicos têm para o início da degradação.

Para avaliar a degradação de diferentes materiais orgânicos, utiliza-se frequentemente o parâmetro meia-vida, definido como o período de tempo necessário para que a metade da quantidade do material considerado se degrade. São relatados valores de meia-vida de 0,16 anos para os açúcares, proteínas e polímeros de carboidratos e de 1980 anos para as substancias húmicas (Jenkinson \& Rayner, 1977). Porém, dentro de um mesmo material, podem ocorrer frações que se degradaram com diferentes velocidades, como destacou Paul (1984). Este autor ajustou equações para caracterizar a degradação de ${ }^{14} \mathrm{C}$-glicose incorporada ao solo e observou que uma fração 
correspondente a $29 \%$ do total adicionado foi degradada mais rapidamente, meia-vida de 2 dias, enquanto outros $41 \%$ apresentaram meia-vida de 30 dias e foram caracterizados como a fração imobilizada pela biomassa microbiana. Os $30 \%$ restantes sofreram decomposição lenta, meia vida de 3450 dias, correspondendo a uma fração altamente estabilizada do solo, na qual parte do carbono da glicose foi incorporado.

\subsection{0 modelo de cinética de primeira ordem}

O estudo da cinética da decomposição de substratos orgânicos envolve a utilização de modelos matemáticos como o modelo de cinética de primeira ordem, que apesar de ser bastante simples, tem sido utilizado com frequência nos estudos de degradação da matéria orgânica (Jenkinson \& Rayner, 1977). Este modelo se baseia no princípio de que a velocidade de decomposição de um determinado substrato, em um determinado instante, é diretamente proporcional à quantidade de substrato presente neste mesmo momento. Como a quantidade de substrato é máxima no início e diminui com o tempo, a velocidade de decomposição é decrescente (Lathan, 1974). Em termos matemáticos o princípio citado é expresso pela equação diferencial:

$$
\frac{d C t}{d t}=k\left(C_{0}-C_{t}\right)
$$

na qual $\mathrm{C}_{0}$ é a quantidade inicial de carbono decomponivel microbiologicamente em $\mathrm{CO}_{2}$ e $\mathrm{H}_{2} \mathrm{O} ; \mathrm{C}_{1}$ é a quantidade de carbono decomposta no tempo t e $k$ é a constante de velocidade de primeira ordem.

A integração desta equação leva à expressão do modelo de cinética de primeira ordem na forma integrada:

$$
C_{t}=C_{0}\left(1-e^{-k t}\right)
$$

A quantidade de carbono remanescente $\left(\mathrm{C}_{\mathrm{r}}\right)$ que ainda será decomposta, poderá ser estimada pela expressão:

$$
\mathrm{C}_{\mathrm{r}}=\mathrm{C}_{0}-\mathrm{C}_{\mathrm{t}}=\mathrm{C}_{0} \mathrm{e}^{-\mathrm{kt}}
$$


Com base na constante $k$, é possível comparar a degradabilidade de compostos orgânicos, em função de sua natureza e condições de incubação. Através desta constante, também é possivel calcular a meia-vida dos compostos orgânicos estudados $(\mathrm{t} 1 / 2)$ pela equação:

$$
\mathrm{t} 1 / 2=\ln 2 / \mathrm{k}
$$




\section{MATERIAL E MÉTODOS}

O presente estudo compreendeu dois experimentos de incubação, envolvendo diferentes materiais orgânicos e tipos de solos. O primeiro avaliou as variações de $\mathrm{pH} \mathrm{e}$ alumínio trocável ocorridas em resposta a incubação de dez materiais em dois solos, enquanto que o segundo estudou a cinética de degradação de cinco dos dez materiais, em um dos solo, buscando relacionar os incrementos à atividade microbiana, promovida pela incubação destes materiais, com as variações de $\mathrm{pH}$ ocorridas no meio.

\subsection{Caracterização dos solos utilizados}

Amostras de terra foram coletadas da camada de $0-20 \mathrm{~cm}$ de um Latossolo Vermelho Amarelo (LV) e um Cambissolo $(\mathrm{Cb})$ na região de Piracicaba - SP. A análise granulométrica e a caracterização química das amostras de terra encontram-se nas Tabelas 1 e 2 , respectivamente.

Tabela 1. Análise granulométrica das amostras de terra utilizadas.

\begin{tabular}{cccc}
\hline Solo & Areia & Silte & Argila \\
\hline & & & \\
$\mathrm{LV}$ & 700 & 60 & 240 \\
$\mathrm{Cb}$ & 180 & 300 & 520 \\
\hline
\end{tabular}


Tabela 2. Caracterização química das amostras de terra utilizadas.

\begin{tabular}{|c|c|c|c|c|c|c|c|c|c|c|c|c|c|}
\hline \multirow[t]{2}{*}{ Solo } & $\mathrm{pH}$ & $\mathrm{pH}$ & \multirow[t]{2}{*}{ C } & \multirow[t]{2}{*}{$\mathrm{P}$} & K & $\mathrm{Ca}$ & $\mathrm{Mg}$ & $\mathrm{Al}$ & $\mathrm{H}+\mathrm{Al}$ & $S$ & $\mathrm{~T}$ & \multirow[t]{2}{*}{$\mathrm{V}$} & \multirow[t]{2}{*}{$\mathrm{m}$} \\
\hline & $\mathrm{H}_{2} \mathrm{O}$ & $\mathrm{CaCl}_{2}$ & & & & & & & & & & & \\
\hline & & & $\mathrm{gdm}^{3}$ & $\mathrm{mgdm}^{-3}$ & $\ldots$ & $\ldots$ & $\ldots$ & $\mathrm{mmol}_{\mathrm{c}}$ & $\mathrm{dm}^{3}-$ & 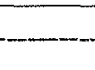 & 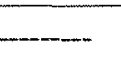 & --9 & 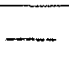 \\
\hline LV & 5,6 & 4,6 & 12,8 & 6 & 0,7 & 14 & 5 & 1 & 38 & 19,7 & 57,7 & 34 & 5 \\
\hline $\mathrm{Cb}$ & 4,8 & 4,1 & 8,1 & 2 & 1,8 & 27 & 10 & 31 & 109 & 38,8 & 147,8 & 26 & 44 \\
\hline
\end{tabular}

\subsection{Caracterização dos materiais orgânicos utilizados}

Materiais orgânicos de natureza variada foram empregados nos experimentos de incubação nos solos. Esperava-se assim, detectar diferentes comportamentos durante o periodo de incubação, em função da composição quimica e do grau de decomposição da fração orgânica dos materiais, que foram os seguintes: palha de cana coletada na época da colheita em usina da região de Piracicaba - SP; parte aérea de feijão de porco (Canovalia ensiformis D.C.), leguminosa empregada como adubo verde; subamostras de esterco bovino, esterco de galinha, composto orgânico, vermicomposto e turfa retiradas de materiais enviados para análise química, ao Departamento de Química da ESALQ; lodo 1 e lodo 2, coletado na Estação de Tratamento de Efluentes da SABESP em Barueri - SP, sendo o primeiro empilhado ao ar livre por um período de 15 meses e o segundo empregado no experimento uma semana após a coleta; vinhaça, resíduo líquido da destilação para fabricação de etanol, coletado em usina da região de Piracicaba - SP.

A Tabela 3 apresenta a caracterização dos materiais orgânicos utilizados no experimento. A matéria seca a $65^{\circ} \mathrm{C}$, a matéria orgânica total e o $\mathrm{pH}$ em água foram determinados de acordo com Brasil (1988). O nitrogênio foi determinado pelo método de Kjeldahl, através de digestão com $\mathrm{H}_{2} \mathrm{SO}_{4}$ das amostras dos materiais secos e moídos, seguida de destilação em meio alcalino. As determinações de carbono foram feitas por volumetria de oxidação-redução, empregando dicromato de potássio em meio ácido, a quente (Rodella \& Alcarde, 1994). O mesmo método foi utilizado na determinação do 


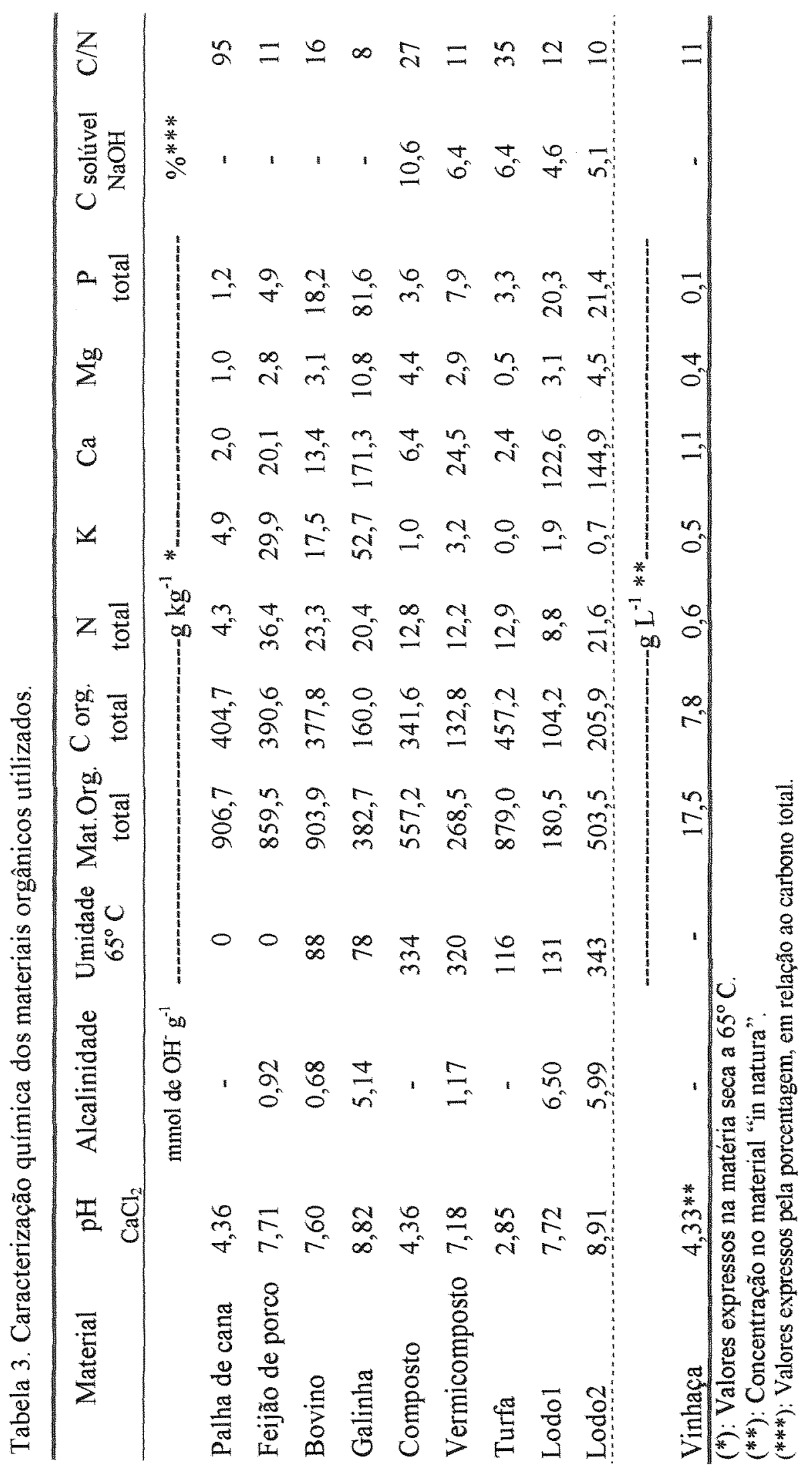


carbono extraido por solução $0,1 \mathrm{~mol} \mathrm{~L}^{-1}$ de $\mathrm{NaOH}$, a qual tem a capacidade de dissolver a fração humificada dos materiais (Bernal et al., 1996), além da fração hidrossolúvel. Por essa determinação ser geralmente efetuada para $o$ acompanhamento das transformações ocorridas durante o processo de compostagem (Roig et al.,1988), como forma de avaliação da maturidade do composto obtido, foi realizada apenas para materiais que, reconhecidamente, passaram por algum processo de compostagem, como os lodos, a turfa, o composto e o vermicomposto.

Os demais elementos foram solubilizados através de digestão nítricoperclórica. $\mathrm{O}$ fósforo foi determinado por espectrofotometria, pelo método do ácido fosfovanadomolíbdico; o potássio por espectrometria de chama de emissão e o cálcio e magnésio por espectrometria de absorção atômica. A alcalinidade dos materiais orgânicos, expressa em mmol $\mathrm{OH}^{-} \mathrm{g}^{-1}$, foi determinada de acordo com o procedimento analítico empregado para determinação do poder de neutralização de rochas calcáreas, (Brasil, 1988). A presença de ín carbonato nos materiais foi determinada qualitativamente pela efervescência observada após adição de $\mathrm{HCl} 0,5 \mathrm{~mol} \mathrm{~L}{ }^{-1}$.

\subsection{Experimento 1 - Efeito da adição de material orgânico sobre o pH e teor de alumínio trocável do solo}

O experimento foi conduzido no período de 04 de novembro de 1997 a 24 de abril de 1998, em casa de vegetação, no Departamento de Química da ESALQ, município de Piracicaba - SP . O delineamento experimental utilizado foi o inteiramente casualizado, empregando esquema fatorial $2 \times 11$, correspondentes a dois solos e dez fontes de matéria orgânica, com três repetições.

As amostras de terra estudadas foram escolhidas com base nos seus valores de pH e alumínio trocável, de modo a fornecerem situações diferenciadas quanto a estes atributos. Já na seleção dos dez materiais orgânicos estudados, optou-se intencionalmente por materiais de diferentes origens, composições químicas e estágios de decomposição, para que se pudesse obter interferências na acidez dos solos. 


\subsubsection{Instalação}

A incubação dos materiais orgânicos foi conduzida à temperatura ambiente, utilizando-se vasos plásticos sem tampa, com $15 \mathrm{~cm}$ de diâmetro superior, $12 \mathrm{~cm}$ de diâmetro inferior e $12 \mathrm{~cm}$ de altura, contendo uma massa de $2,0 \mathrm{~kg}$ de terra fina seca ao ar.

Diante da necessidade de se uniformizar a dose dos diferentes materiais orgânicos, adotou-se o critério de fornecer aos solos uma mesma quantidade de carbono orgânico, suficiente para elevar o teor nos solos em 0,2 unidade percentual. A Tabela 4 relaciona as doses dos materiais aplicadas para $2,0 \mathrm{~kg}$ de terra e seus valores correspondentes por unidade de área.

Tabela 4. Doses dos materiais aplicadas nos $2,0 \mathrm{~kg}$ de terra e seus valores correspondentes por unidade de área.

\begin{tabular}{lccc}
\hline Material & Forma & \multicolumn{2}{c}{ Doses } \\
\hline & & g por vaso & $\mathrm{Mg} \mathrm{ha}^{-1}$ \\
Palha de cana & Seco em estufa a $65^{\circ} \mathrm{C}$ & 9,9 & 12,8 \\
Feijão de porco & Seco em estufa a $65^{\circ} \mathrm{C}$ & 10,2 & 13,3 \\
Bovino & Seco ao ar & 11,6 & 15,1 \\
Galinha & Seco ao ar & 27,1 & 35,2 \\
Composto & Seco ao ar & 17,6 & 22,8 \\
Vermicomposto & in natura & 44,3 & 57,6 \\
Turfa & Seco ao ar & 9,9 & 12,9 \\
Lodo1 & Seco ao ar & 44,2 & 57,4 \\
Lodo2 & Seco ao ar & 29,5 & 38,4 \\
& & mL por vaso & $\mathrm{m}^{3}$ ha \\
& & $512 *$ & 666 \\
\hline
\end{tabular}


Após a incorporação dos materiais sólidos em toda a massa de terra, os vasos foram irrigados com água destilada nas quantidades de $330 \mathrm{e} 400 \mathrm{~mL}$ para os solos LV e $\mathrm{Cb}$, respectivamente. As quantidades de água adicionadas foram correspondentes a 70\% da capacidade máxima de retenção de água de cada solo. Após a primeira irrigação, a umidade da terra dos vasos foi mantida constante durante todo o periodo de incubação, através de adições periódicas de água destilada de acordo com a variação da massa dos vasos.

\subsubsection{Variáveis analisadas}

Durante o período de 175 dias de incubação, foram realizadas 11 amostragens de terra dos vasos, em intervalos de tempo que variaram em função do comportamento dos parâmetros avaliados. $\mathrm{O} \mathrm{pH}$ das amostras de terra secas em estufa à $65^{\circ} \mathrm{C}$ foi determinado potenciometricamente, em $\mathrm{H}_{2} \mathrm{O}$ e em $\mathrm{CaCl}_{2} 0,01 \mathrm{~mol} \mathrm{~L} \mathrm{~L}^{-1}$, com relação solo:solução de 1:2,5. As medidas foram feitas após agitações intermitentes durante meia hora. Extraiu-se também o alumínio trocável com solução de $\mathrm{KCl} 1 \mathrm{~mol} \mathrm{~L}^{-1}$, o qual foi determinado por volumetria de neutralização e por espectrofotometria, empregandose como reagente cromogenico o alaranjado de xilenol, como descrito por Pritchard (1967). A opção de utilizar o segundo método se deve ao fato do método volumétrico contabilizar toda a acidez extraída pelo $\mathrm{KCl} 1 \mathrm{~mol} \mathrm{~L}^{-1}$ como alumínio, embora esta também inclua íons hidrogênio adsorvidos às cargas negativas dos colóides do solo.

Os resultados de $\mathrm{pH}\left(\mathrm{H}_{2} \mathrm{O}\right), \mathrm{pH}\left(\mathrm{CaCl}_{2}\right)$, Al determinado por volumetria e por espectrofotometria foram analisados estatisticamente, procedendo-se análise de variância e comparação de médias dos tratamentos pelo teste de Tukey.

Para se testar a hipótese de que o alumínio estaria sendo complexado por compostos orgânicos, acompanhou-se o processo de incubação para a determinação da época correspondente ao maior decréscimo nos valores de alumínio trocável, e com base nesta informação, determinou-se o alumínio extraído em solução de $\mathrm{CuCl}_{2} 0,5 \mathrm{~mol} \mathrm{~L}^{-1}$, como descrito por Juo \& Kamprath (1979), nas amostras de terra correspondentes à 
amostragem do $63^{\circ}$ dia de incubação. Esse procedimento foi efetuado apenas no $\mathrm{Cb}$, pois apenas neste solo tinha sido observado um abaixamento no teor de alumínio que possibilitaria destacar o efeito complexante dos compostos orgânicos. Na extração com cloreto de cobre fez-se agitação de $5 \mathrm{~g}$ de amostra de terra com $50 \mathrm{~mL}$ de solução de $\mathrm{CuCl}_{2}, 5,5 \mathrm{~mol} \mathrm{~L}^{-1}$ por uma hora. A separação do sobrenadante foi feita por centrifugação e a determinação da concentração de alumínio por espectrometria de absorção atômica em chama de óxido nitroso-acetileno.

O cálculo da fração do alumínio do solo complexado pela matéria orgânica, foi efetuado conforme descrito por Myazawa et al. (1993), considerando-se tal fração como a diferença entre os teores de alumínio extraído por $\mathrm{CuCl}_{2}$ e $\mathrm{KCl}$, conforme indicado pelas seguintes relações:

$\triangle \mathrm{Al}=\mathrm{Al}\left(\mathrm{CuCl}_{2}\right)-\mathrm{Al}(\mathrm{KCl}) ;$

$\mathrm{Al}$ complexo orgânico $=\Delta \mathrm{Al}$ (tratamento) $-\Delta \mathrm{Al}$ (testemunha)

Contribuição complexo orgânico $=\frac{\mathrm{Al} \text { complexo orgânico } \times 100}{\mathrm{Al} \mathrm{KCl}(\text { testemunha) }-\mathrm{Al} \mathrm{KCl} \text { (tratamento) }}$

Contribuição $\mathrm{pH}=100$ - Contribuição complexo orgânico (\%)

\subsection{Experimento 2 - Relação entre a degradação microbiana da matéria orgânica c o pH do solo.}

O experimento foi conduzido no período de 22 de maio a 08 de julho 1998 , em câmaras de incubação, para determinação de DBO (Demanda Bioquímica de Oxigênio) no Laboratório de Química Analítica do Departamento de Química da ESALQ/USP, Piracicaba -SP. O delineamento experimental utilizado foi inteiramente casualizado com seis repetições, estudando-se cinco materiais orgânicos. Com a finalidade de se obter diferentes velocidades de decomposição destes materiais e assim verificar a influência da atividade microbiana no $\mathrm{pH}$ do solo, o experimento foi conduzido nas temperaturas de incubação de 20 e $30^{\circ} \mathrm{C}$. Após 38 dias de incubação, quando as curvas de liberação de $\mathrm{CO}_{2}$ acumulado da maioria materiais já apresentavam 
uma tendência assintótica, indicando baixa velocidade de produção de $\mathrm{CO}_{2}$, as temperaturas foram elevadas a $35^{\circ} \mathrm{C}$.

Para este experimento, foi empregado apenas o $\mathrm{Cb}$, selecionado em função do seu maior teor de alumínio trocável para evidenciar um maior efeito dos materiais orgânicos. Como neste caso a incubação foi conduzida sob condições controladas de temperatura, a limitação de espaço na câmara incubadora apenas possibilitou a avaliação dos materiais: feijão de porco, esterco bovino, vinhaça, lodo 1 e turfa, procurando-se manter uma diversificação na natureza dos materiais.

\subsubsection{Instalação}

A incubação foi conduzida em potes de vidro com tampas plásticas, com capacidade de $1 \mathrm{~L}$, contendo uma massa de $0,5 \mathrm{~kg}$ de terra fina seca ao ar. Da mesma forma que no experimento 1 , adotou-se o critério de uniformizar as doses dos materiais orgânicos pelo teor de carbono, de modo a fornecer ao solo 0,2 unidade percentual deste elemento. A Tabela 5 mostra as doses dos materiais aplicadas a $0,5 \mathrm{~kg}$ de terra e suas correspondentes em megagramas por hectare. Cada pote recebeu $100 \mathrm{~mL}$ de água destilada após a incorporação dos materiais sólidos, a fim de atingir umidade correspondente a $70 \%$ da capacidade máxima de retenção de água do solo. Já a vinhaça, a exemplo do Ensaio 1, foi concentrada através de evaporação a $100^{\circ} \mathrm{C}$, até atingir o volume desejado.

Três das seis repetições de cada tratamento foram destinadas a avaliação da atividade microbiana através da medida da quantidade de $\mathrm{CO}_{2}$ produzida, enquanto as outras três serviram para retirada de amostras nas quais foram realizadas medidas de $\mathrm{pH}$ em $\mathrm{CaCl}_{2}$ 0,01 mol $\mathrm{L}^{-1}$. Dentro dos potes destinados a respirometria, foram acondicionados frascos plásticos de $100 \mathrm{~mL}$, contendo $40 \mathrm{~mL}$ de solução aproximadamente $0,5 \mathrm{~mol} \mathrm{~L}{ }^{-1}$ de $\mathrm{NaOH}$, com a finalidade de absorver o $\mathrm{CO}_{2}$ liberado durante a respiração microbiana. Cada pote, devidamente tampado, foi levado à câmara de incubação regulada para a sua respectiva temperatura. 
Tabela 5. Doses dos materiais aplicadas nos potes do ensaio 2 e seus valores correspondentes por unidade de área.

\begin{tabular}{lccc}
\hline \multicolumn{1}{c}{ Material } & Forma & \multicolumn{2}{c}{ Doses } \\
\hline & & $\mathrm{g} 0,5 \mathrm{~kg}^{-1}$ & $\mathrm{Mg} \mathrm{ha}^{-1}$ \\
Feijão de porco & Seco em estufa a $65^{\circ} \mathrm{C}$ & 2,6 & 13,3 \\
Bovino & Seco ao ar & 2,9 & 15,1 \\
Turfa & Seco ao ar & 2,5 & 12,9 \\
Lodo1 & Seco ao ar & 11,0 & 57,4 \\
& & $\mathrm{~mL} 0,5 \mathrm{~kg}^{-1}$ & $\mathrm{~m}^{3} \mathrm{ha}^{-1}$ \\
Vinhaça & in natura & 128 & 666 \\
\hline
\end{tabular}

\subsubsection{Variáveis analisadas}

Os frascos contendo solução de $\mathrm{NaOH}$ foram retirados dos potes de incubação em intervalos variáveis, vedados e substituidos por outros para captação de $\mathrm{CO}_{2}$ durante um novo periodo. No decorrer dos 71 dias de incubação, foram feitas 20 trocas da solução de $\mathrm{NaOH}$, nas quais foi determinada a quantidade de $\mathrm{CO}_{2}$ liberada em cada período, pelo método condutimétrico descrito por Rodella (1996). Os frascos contendo solução de $\mathrm{NaOH}$ com o íon $\mathrm{CO}_{3}{ }^{2-}$ produzido foram colocados em banho-maria à temperatura ambiente por 30 minutos para homogeneização da temperatura. No mesmo banho foram também colocados frascos com as soluções padronizadas de $\mathrm{NaOH}$ empregada na captura de $\mathrm{CO}_{2}$ e de $\mathrm{Na}_{2} \mathrm{CO}_{3}$, que constituíram as soluções padrões para calibração do método na quantificação de $\mathrm{CO}_{2}$. No método condutimétrico, a solução padrão de $\mathrm{Na}_{2} \mathrm{CO}_{3}$ correspondeu à solução de $\mathrm{NaOH}$ usada na absorção de $\mathrm{CO}_{2}$ após ter sido totalmente carbonatada.

Nos mesmos intervalos de tempo das determinação de $\mathrm{CO}_{2}$, foram retiradas amostras nos potes destinados à determinação de $\mathrm{pH}$, a qual foi realizada em solução de $\mathrm{CaCl}_{2} 0,01 \mathrm{~mol} \mathrm{~L}^{-1}$ com relação solo:solução de 1:2,5. Aos 38 dias de incubação, realizou-se também determinação do alumínio trocável do solo por volumetria de neutralização. 


\section{RESULTADOS E DISCUSSÃO}

\subsection{Experimento 1 - Efeito da adição de material orgânico sobre o pH e teor de alumínio trocável do solo.}

\subsection{1 $\mathrm{pH}$ em $\mathrm{CaCl}_{2}$}

A variação do $\mathrm{pH}\left(\mathrm{CaCl}_{2}\right)$ do $\mathrm{LV}$ e do $\mathrm{Cb}$ no decorrer dos 175 dias de incubação é apresentada na Figura 1, na qual se observa que a maior parte dos materiais orgânicos incorporados promoveu a elevação deste atributo em ambos os solos. Esse aumento foi significativo ao nivel de $5 \%$ pelo teste de Tukey, conforme se constata no Apêndice 1. As exceções para esta tendência foram o composto orgânico e a turfa, provavelmente por se tratarem de materiais com maior grau de estabilização, evidenciado por consideráveis teores de carbono extraído por $\mathrm{NaOH}$ (Tabela 3 ).

No $L V$, a turfa promoveu significativa redução de $\mathrm{pH}$ em relação a testemunha devido a sua natureza ácida, o que não se verificou no $\mathrm{Cb}$ que, apresentando um $\mathrm{pH}$ bem mais baixo, não foi influenciado pela acidez da turfa. Na Figura 1 observase que o composto orgânico não alterou o $\mathrm{pH}\left(\mathrm{CaCl}_{2}\right)$ de nenhum dos solos estudados. $\mathrm{O}$ fato destes dois materiais não terem elevado o $\mathrm{pH}\left(\mathrm{CaCl}_{2}\right)$ do solo durante a incubação, está de acordo com as observações de Eira \& Carvalho (1970) que se referem aos materiais mais estabilizados como sendo menos efetivos no aumento do $\mathrm{pH}$. Possivelmente uma reduzida alteração microbiana da turfa no solo, aliada a sua maior acidez, tenha contribuído para que a incorporação deste material resultasse em valores de $\mathrm{pH}$ mais baixos que o tratamento testemunha. 


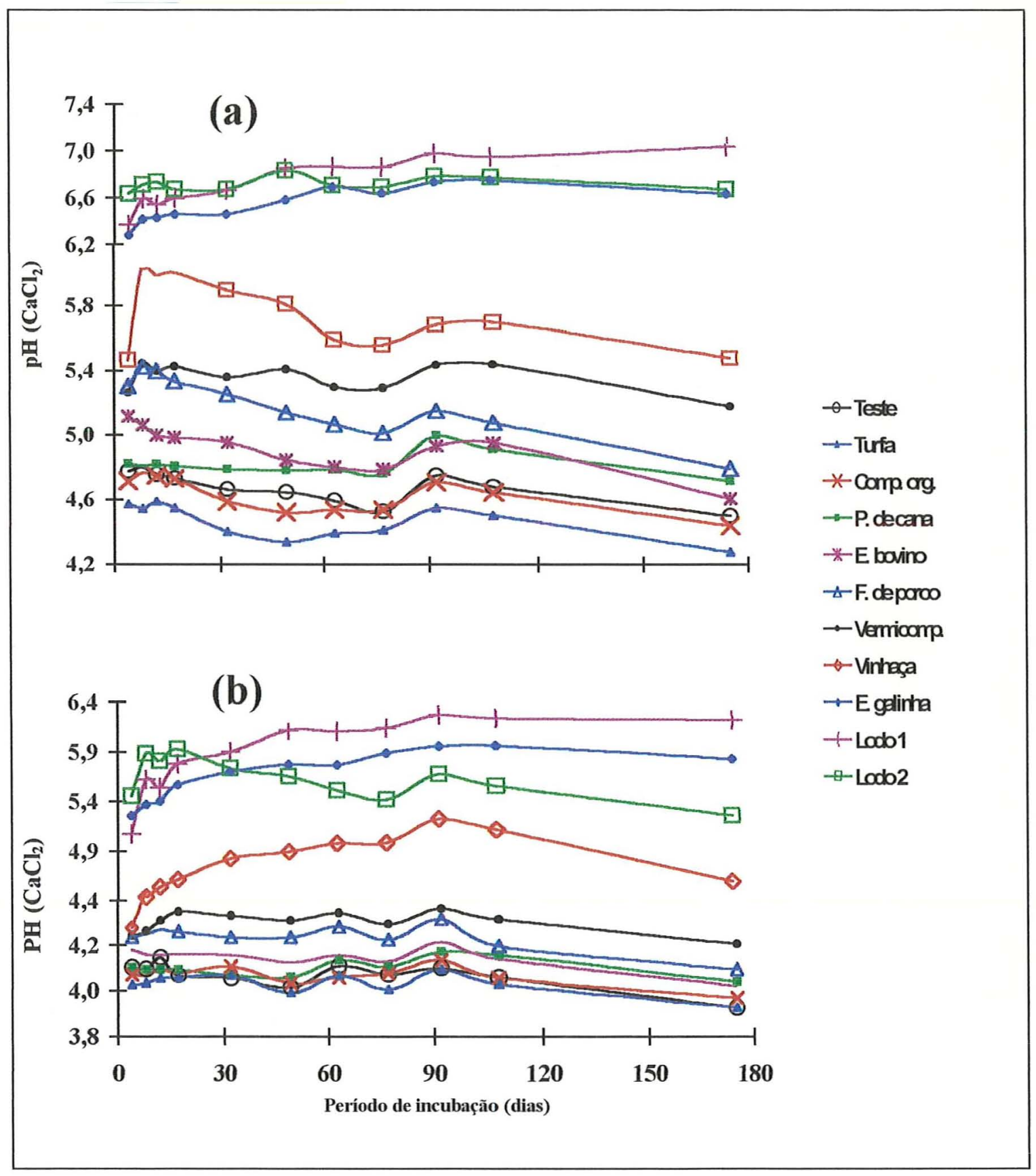

Figura 1. Valores de $\mathrm{pH}$ em $\mathrm{CaCl}_{2}$ dos tratamentos em função do tempo. (a) Latossolo Vermelho Amarelo; (b) Cambissolo. 
Entre os materiais que promoveram acréscimos no $\mathrm{pH}\left(\mathrm{CaCl}_{2}\right)$ do $\mathrm{LV}$, é possivel relacionar as diferenciações de comportamento com a composição química apresentada na Tabela 3. O tratamento com palha de cana não apresentou interferência nos valores de $\mathrm{pH}\left(\mathrm{CaCl}_{2}\right)$ inicial, supostamente por não apresentar nenhuma capacidade alcalinizante, conforme indicado pelo baixo valor de $\mathrm{pH}$ desse material. Contudo, verificou-se que, com o passar do tempo, a incubação da palha de cana promoveu um lento aumento do $\mathrm{pH}\left(\mathrm{CaCl}_{2}\right)$ até aproximadamente o $80^{\circ}$ dia de incubação, a partir de quando não mais variou em relação à testemunha . O fato dessa alteração de $\mathrm{pH}$ só ser significativa a partir do $17^{\circ}$ dia de incubação (Apêndice 1) constitui-se numa evidência de que esta tenha ocorrido em função da transformação microbiana do material durante o período de incubação, como concluiu o trabalho de Rodella et al. (1983). É possível que a menor velocidade de alteração do $\mathrm{pH}\left(\mathrm{CaCl}_{2}\right)$ promovida pela palha de cana no $\mathrm{LV}$ tenha ocorrido devido a dificuldade de decomposição, geralmente observada para materiais com elevada relação $\mathrm{C} / \mathrm{N}$.

Os tratamentos com incorporação de esterco bovino, feijão de porco e vermicomposto promoveram elevações significativas no $\mathrm{pH}\left(\mathrm{CaCl}_{2}\right)$ do $\mathrm{LV}$ já na primeira época de amostragem, o que é consequência da natureza alcalina desses materiais (Tabela 3). Nota-se que enquanto o solo tratado com vermicomposto sofreu uma elevação inicial de $\mathrm{pH}\left(\mathrm{CaCl}_{2}\right)$ e depois acompanhou as variações do tratamento testemunha, os tratamentos com esterco bovino e feijão de porco apresentaram uma queda mais acentuada e $\mathrm{pH}$, embora os valores deste atributo, ao final do período de incubação, tenham permanecido maiores que o da testemunha. Tal comportamento foi observado por Yan et al. (1997), após a incorporação de restos de leguminosa. A redução do $\mathrm{pH}$ após um considerável aumento foi atribuído pelos autores ao processo de nitrificação, o que estaria de acordo com os maiores teores de nitrogênio nessa espécie vegetal. 
Houve, em todas as épocas de amostragem, uma aumento estatisticamente significativo no $\mathrm{pH}$ do $\mathrm{LV}$, em resposta a aplicação da vinhaça, sendo que a diferença mais expressiva entre esse tratamento e a testemunha ocorreu no $8^{\circ}$ dia de incubação. A partir deste ponto, a referida diferença se manteve constante e significativa até o final do periodo de incubação. É provável que a maior velocidade de alteração do $\mathrm{pH}\left(\mathrm{CaCl}_{2}\right)$ pela vinhaça esteja relacionada com a facilidade com que este material se degrada no solo, visto que cerca de $90 \%$ do seu carbono encontra-se na forma solúvel. Apesar do caráter ácido deste material, a rápida degradação desencadeia um mecanismo de aumento de $\mathrm{pH}$, que Leal et al. (1983) atribuem ao processo de redução no solo pela intensa respiração, e consequente consumo de íons $\mathrm{H}^{+}$.

$\mathrm{O}$ esterco de galinha e os dois lodos de esgoto foram os materiais que mais elevaram o $\mathrm{pH}\left(\mathrm{CaCl}_{2}\right)$ do solo, sempre diferindo estatisticamente dos demais materiais nas diferentes épocas de amostragem. Verifica-se na Figura 1 que os dois lodos alteraram de maneira diferente o $\mathrm{pH}\left(\mathrm{CaCl}_{2}\right)$ nas amostras de terra do $\mathrm{LV}$ durante o período de incubação. Embora o tratamento com lodo 2, tenha apresentado um valor de $\mathrm{pH}\left(\mathrm{CaCl}_{2}\right)$ inicial estatisticamente maior que os demais materiais (Apêndice 1), o aumento deste atributo em relação a testemunha permaneceu constante em todas avaliações. Por outro lado, o lodo 1 proporcionou um progressivo aumento do $\mathrm{pH}\left(\mathrm{CaCl}_{2}\right)$ em relação a testemunha, chegando a superar o aumento promovido pelo lodo 2 aos 63 dias.

Materiais orgânicos com elevada alcalinidade como lodos de esgoto, aumentam o $\mathrm{pH}$ do solo independentemente das transformações da matéria orgânica no solo (Korcak, 1980). Assim sendo, a alteração do $\mathrm{pH}\left(\mathrm{CaCl}_{2}\right)$ do solo com o tempo promovida pela incubação do lodo 1 não poderia ser atribuida a essas transformações. $\mathrm{E}$ provável que a diferença de comportamento entre os lodos esteja relacionada à reatividade dos constituintes inorgânicos responsáveis pelo aumento do $\mathrm{pH}$ em cada material. 
A cal viva, $\mathrm{CaO}$, adicionada durante o processo de obtenção de lodos, reage com a água para formar hidróxido de cálcio, $\mathrm{Ca}(\mathrm{OH})_{2}$, que é uma base forte e reage prontamente com componentes da acidez do solo. Esta base, com o tempo, passa por um processo de carbonatação através da reação com $\mathrm{o} \mathrm{CO}_{2}$ do ar atmosférico, podendo resultar na sua completa transformação em carbonato de cálcio, $\mathrm{CaCO}_{3}$. Embora o lodo continue com a mesma alcalinidade, a formação da base fraca $\mathrm{CO}_{3}{ }^{2-}$ determina uma redução do seu $\mathrm{pH}$ e da velocidade de neutralização da acidez do solo. Este fenômeno poderia explicar o comportamento dos lodos utilizados no experimento, já que os dois materiais possuem tempos de armazenagem diferentes. $\mathrm{O}$ lodo 2 , recém trazido da estação de tratamento, possivelmente tinha a maior parte de seu agente alcalinizante na forma de $\mathrm{Ca}(\mathrm{OH})_{2}$, o que lhe conferiu um maior $\mathrm{pH}$ e uma reação de neutralização de acidez quase que instantânea.

Estando o lodo 1 armazenado ao ar livre por 15 meses, a alcalinidade deste material era devida principalmente ao $\mathrm{CaCO}_{3}$, cuja presença foi detectada qualitativamente. Explica-se assim os menores valores de $\mathrm{pH}\left(\mathrm{CaCl}_{2}\right)$ inicial do tratamento e posterior aumento com o tempo. O fato do valor de $\mathrm{pH}$ final do lodo 1 ter sido muito maior que o do lodo 2 , pode ser explicado pela incorporação de uma maior quantidade do primeiro material (Tabela 4 ).

A incubação do esterco de galinha resultou num grande aumento no $\mathrm{pH}\left(\mathrm{CaCl}_{2}\right)$ inicial do $\mathrm{LV}$, proporcionando o aumento progressivo deste atributo, em relação a testemunha, até o $63^{\circ}$ dia de incubação. A elevação do $\mathrm{pH}$ do solo pela adição de esterco de galinha foi atribuída por Ernani \& Gianello (1983) entre outros fatores "à difusão da amônia liberada da decomposição do resíduo orgânico". No presente estudo, o teor de cálcio do esterco de galinha sugeriu que haveria outro composto inorgânico, além da amônia, contribuindo para sua alcalinidade. Da mesma forma que para o lodo 1 , a análise qualitativa do esterco de galinha identificou a presença de íon carbonato, o que também explica a alteração do $\mathrm{pH}$ com o periodo de incubação, promovida pela incubação desse material. 
Com algumas exceções, a variação do $\mathrm{pH}\left(\mathrm{CaCl}_{2}\right)$ no $\mathrm{Cb}$ em função da incubação dos materiais orgânicos (Figura 1) se assemelhou ao descrito para o LV. Embora a tendência geral de alteração tenha sido similar nos dois solos, a amplitude destas foi reduzida devido a maior acidez do $\mathrm{Cb}$ (Tabela 2). Em consequência, materiais orgânicos, cuja incorporação no $\mathrm{LV}$ causaram aumento significativo no $\mathrm{pH}\left(\mathrm{CaCl}_{2}\right)$ em relação a testemunha, não causaram nenhum efeito sobre esse atributo no $\mathrm{Cb}$, para a maioria das épocas de avaliação (Apêndice 1).

O tratamento com vinhaça apresentou a diferença mais marcante de comportamento do $\mathrm{pH}\left(\mathrm{CaCl}_{2}\right)$ entre os solos. Este material, quando incubado no $\mathrm{Cb}$, causou um aumento do $\mathrm{pH}$ mais lento que o observado no LV (Figura 1a), prolongandose até o $92^{\circ}$ dia de incubação. Essa observação sugere que o mecanismo responsável pela referida alteração foi de alguma forma retardado nas condiçães de incubação do $\mathrm{Cb}$. É provável que a maior acidez deste solo tenha dificultado a degradação de mateira orgânica por microorganismos, como observaram Anderson \& Joergensen, (1997), e a consequente atuação de substâncias no sentido de alterar o pH.

\subsection{2 $\mathrm{pH} \mathrm{em} \mathrm{H}_{2} \mathrm{O}$}

De modo geral, em ambos os solos estudados, o efeito dos tratamentos sobre o $\mathrm{pH}\left(\mathrm{H}_{2} \mathrm{O}\right)$ foi semelhante ao verificado para o $\mathrm{pH}\left(\mathrm{CaCl}_{2}\right)$, de forma que aspectos levantados na interpretação do comportamento deste último atributo também são válidos para o $\mathrm{pH}\left(\mathrm{H}_{2} \mathrm{O}\right)$. Essa similaridade pode ser constatada nas Figuras 2 e 3 , que apresentam a variação do $\mathrm{pH}\left(\mathrm{H}_{2} \mathrm{O}\right)$ para os tratamentos estudados nas amostras de terra dos dois solos. No Apêndice 2 encontram-se as médias dessas medidas de $\mathrm{pH}$ para os tratamentos referentes aos dois solos estudados, nas diferentes épocas de amostragem, bem como a comparação das mesmas pelo Teste de Tukey. 


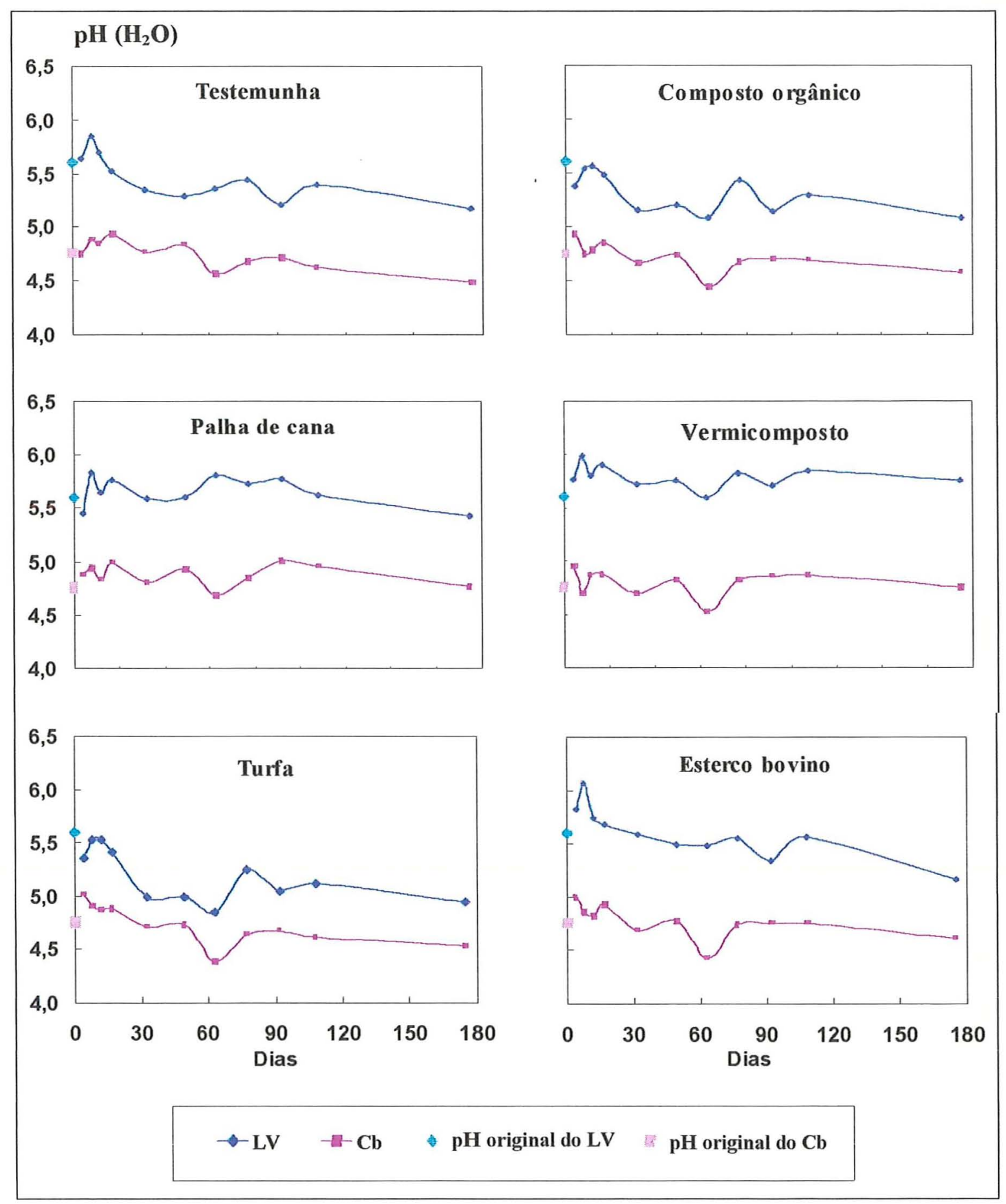

Figura 2. Valores de $\mathrm{pH}$ em $\mathrm{H}_{2} \mathrm{O}$ do Latossolo Vermelho Amarelo (LV) e do Cambissolo $(\mathrm{Cb})$, em função da incubação de cada material orgânico. 


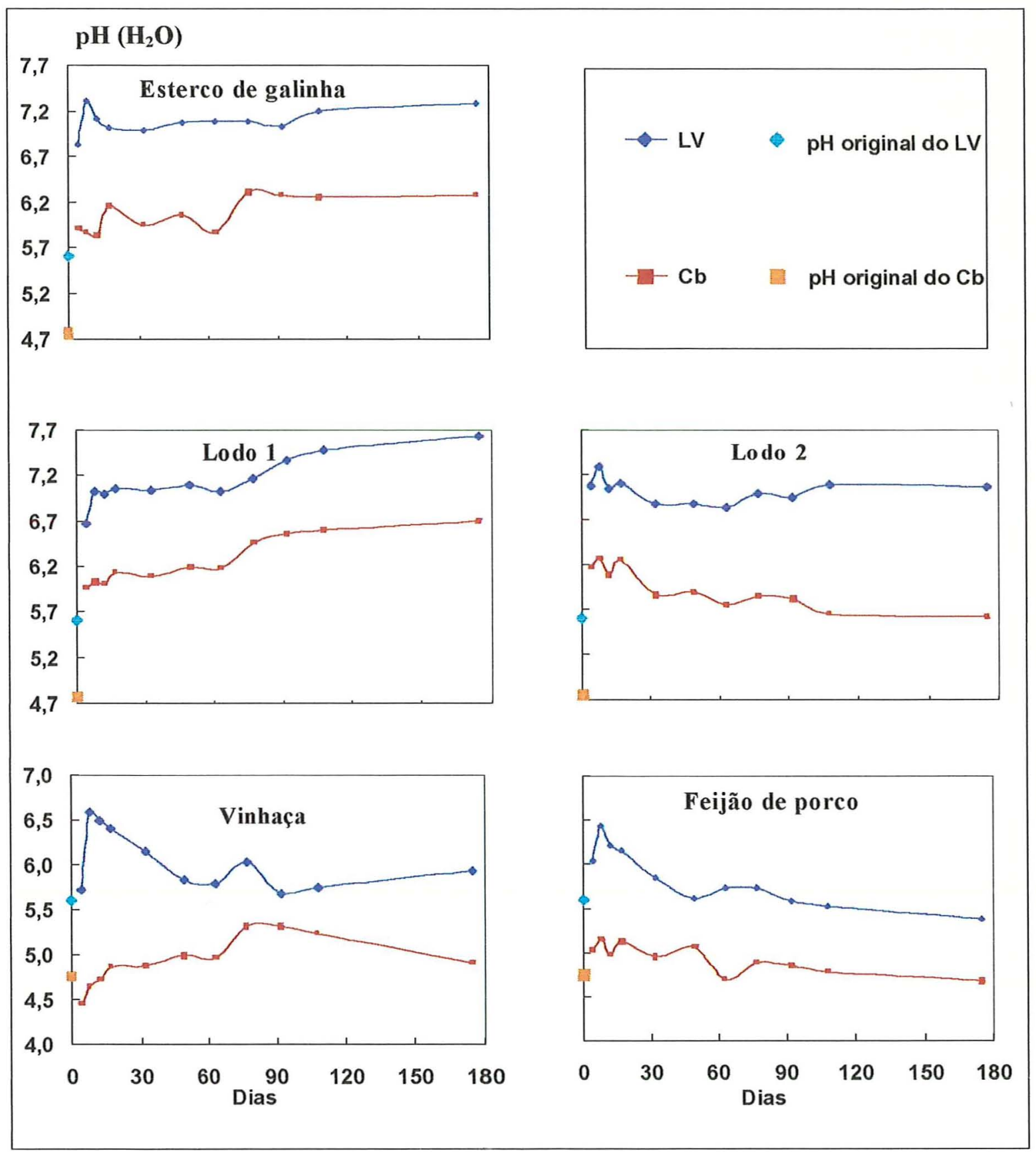

Figura 3. Valores de $\mathrm{pH}$ em $\mathrm{H}_{2} \mathrm{O}$ do Latossolo Vermelho Amarelo (LV) e do Cambissolo $(\mathrm{Cb})$, em função da incubação de cada material orgânico. 


\subsubsection{Al trocável}

Os dois métodos empregados para determinação de alumínio trocável no solo apresentaram resultados diferentes. Os teores de alumínio determinados por espectrofotometria foram menores, em média $14 \%$ para o $\mathrm{Cb}$ e $64 \%$ para o $\mathrm{LV}$, do que aqueles determinados por volumetria de neutralização, conforme indicado na Figura 4. Os menores teores de alumínio, encontrados pelo primeiro método, provavelmente se devem à limitação do alaranjado de xilenol em reagir com todas as formas de alumínio extraídas pela solução de $\mathrm{KCl} 1 \mathrm{~mol} \mathrm{~L}^{-1}$. Por outro lado, a maior diferença observada no LV, provavelmente ocorreu em função da dificil detecção dos reduzidos teores de alumínio trocável desse solo, o que pode ter levado a erros operacionais capazes de superestimar tais teores.
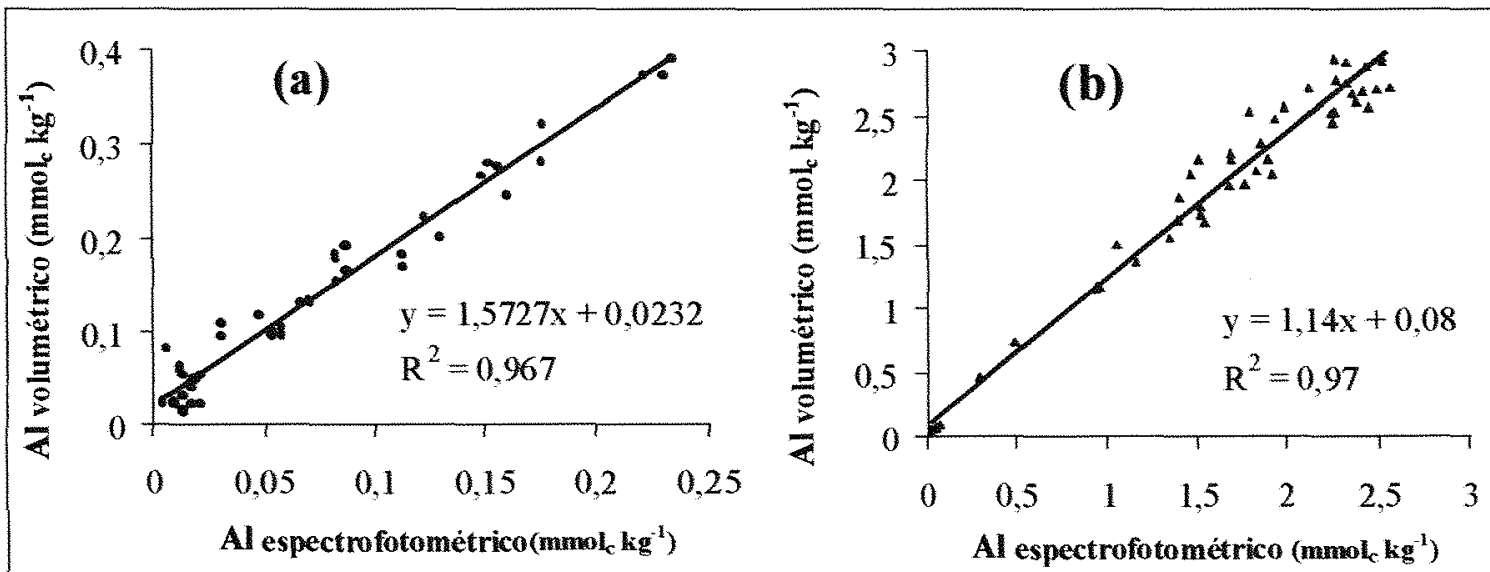

Figura 4. Relação entre teores de alumínio trocável determinados por espectrofotometria e por volumetria de neutralização: (a) Latossolo Vermelho Amarelo; Cambissolo.

A Figura 5 e a Tabela 6 mostram as variações do alumínio trocável determinado por espectrofotometria e por volumetria de neutralização, respectivamente, durante a incubação dos materiais orgânicos nos dois solos. 


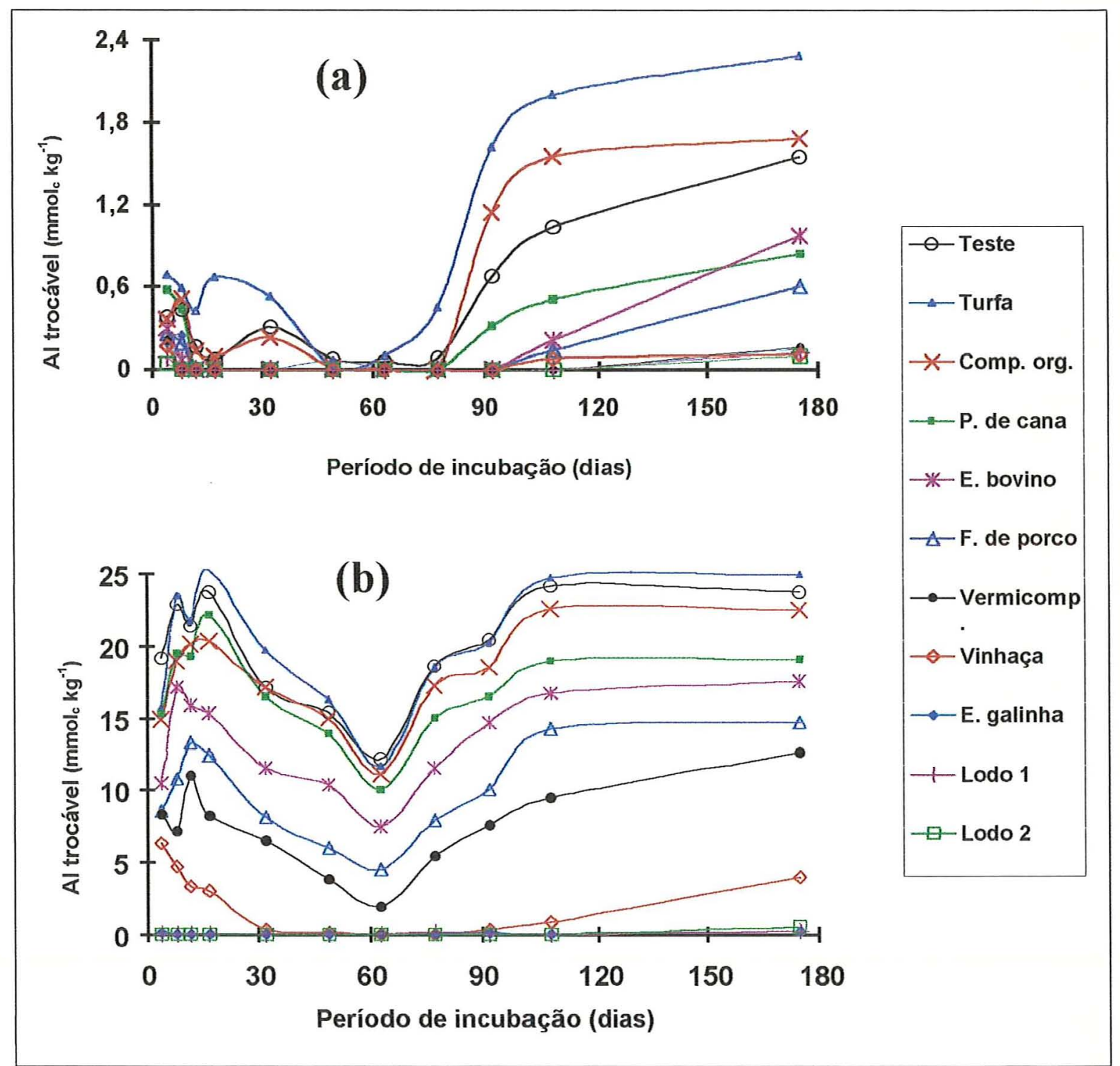

Figura 5. Teores de alumínio trocável determinados por espectrofotometria durante o período de incubação de diferentes materiais orgânicos: (a) Latossolo Vermelho Amarelo; (b) Cambissolo. 


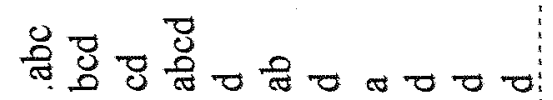
त. .

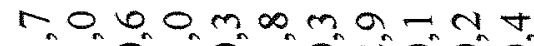
पी 요요요

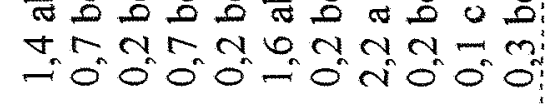
$\pi \pi \pi \pi \pi \pi \pi \pi \pi \approx \pi$

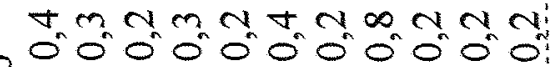
$\frac{0}{0}$

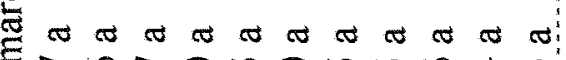

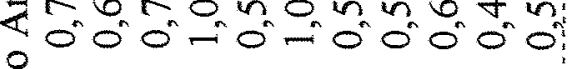

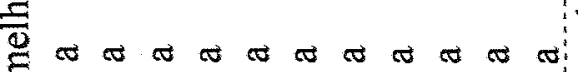

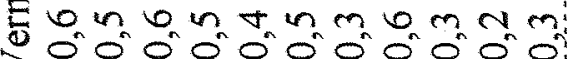
응 응

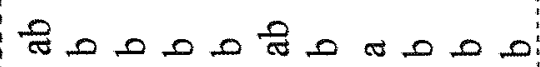

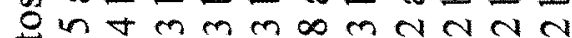

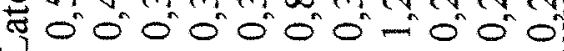

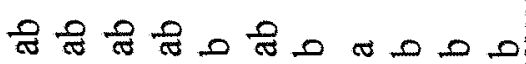
=0

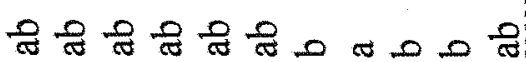

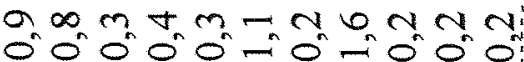

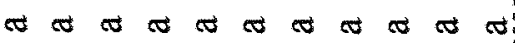
$\infty \mathrm{N}+\mathrm{mO}^{2}=6-\mathrm{C}$

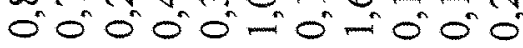

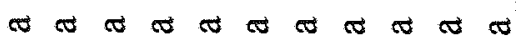

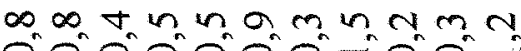
$0000000-00$ -

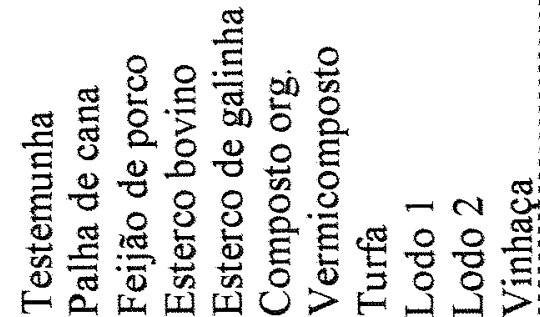

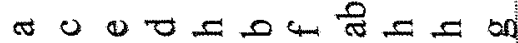

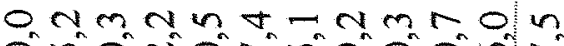

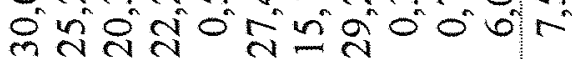

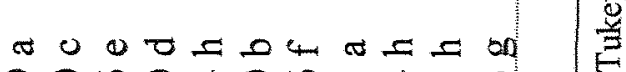

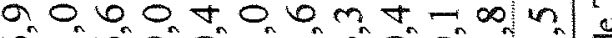

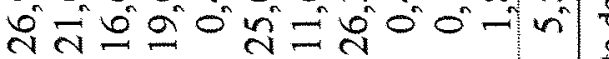

* 000 ons 0 - 0 on on on $\frac{0}{8}$

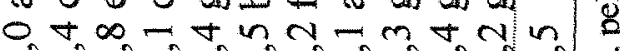

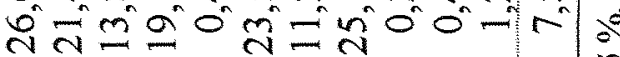
« 000 on 0 \% on on 8 om n

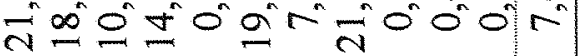
r 000 on 0 फ a m

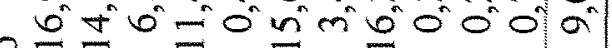
8

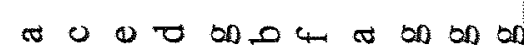
E न $\approx 000$ on 000 on 0 \% वेक की n

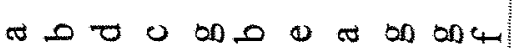
a n $\mathrm{n}$.

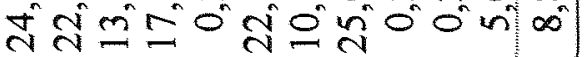
है m $-\mathrm{n}$.

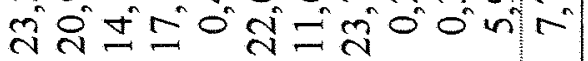

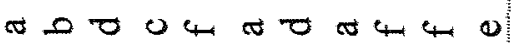
mannton n

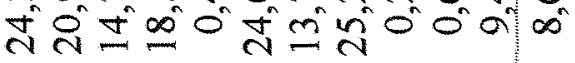

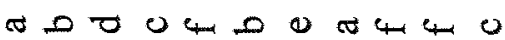
n

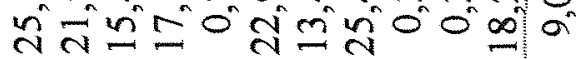

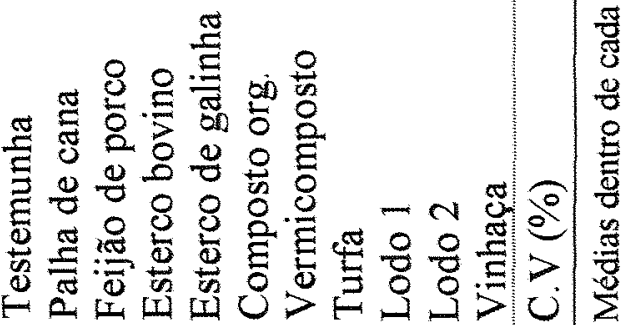


Durante todo periodo de incubação estudado, os diferentes materiais orgânicos não alteraram significativamente os teores de alumínio trocável do $L V$ em relação à testemunha (Apêndice 3), apesar de se observar na Figura 5 que, para a maioria dos materiais, o teor de alumínio trocável do LV mostrou tendência de aumento a partir do $77^{\circ}$ dia de incubação.

$\mathrm{A}$ incubação do $\mathrm{Cb}$ promoveu uma redução dos teores de alumínio trocável até o $63^{\circ}$ dia, na maioria dos materiais tratamentos, com uma posterior elevação dos mesmos (Figura 5). A vinhaça apresentou um comportamento ligeiramente diferenciado dos demais materiais, eliminando o alumínio trocável entre o $33^{\circ}$ e $92^{\circ}$ dia de incubação, sendo que após este período, o teor deste elemento voltou a aumentar lentamente até o final do experimento. Os tratamentos com lodo e com esterco de galinha foram os mais efetivos na redução do alumínio trocável, já que o eliminaram por completo do solo desde a primeira avaliação até o final do experimento.

Todos os materiais, com exceção da turfa, diminuíram significativamente os teores de alumínio trocável do $\mathrm{Cb}$, em relação a testemunha, na maior parte das avaliações (Apêndice 3). É provável que este comportamento diferenciado da turfa seja devido a sua natureza mais ácida.

A Tabela 7 traz os valores de aluminio do Cambissolo extraido por $\mathrm{CuCl}_{2} \mathrm{e}$ por $\mathrm{KCl}$ no $63^{\circ}$ dia de incubação. Como era de se esperar, os teores deste elemento extraidos por $\mathrm{CuCl}_{2}$ em todos tratamentos foram bem maiores, já que a solução deste sal extrai, além do alumínio trocável, o aluminio associado à matéria orgânica. Nas considerações que se seguem, admite-se que a diferença entre os teores de alumínio extraídos pelos referidos extratores corresponde ao alumínio complexado pela matéria orgânica (Mendonça, 1995). Assim sendo, a quantidade de alumínio complexado para cada material orgânico, bem como a contribuição deste processo na redução dos teores de alumínio trocável, foram calculados segundo descrito por Miyazawa et al. (1993) e também apresentados na Tabela 7 . 
Tabela 7. Teores de $\mathrm{Al}$ complexado pelos materiais orgânicos e a contribuição deste processo e do aumento do $\mathrm{pH}$ na redução do $\mathrm{Al}$ trocável.

\begin{tabular}{|c|c|c|c|c|c|c|}
\hline \multirow[t]{2}{*}{ Tratamento } & \multicolumn{4}{|c|}{$\mathrm{Al}$} & \multicolumn{2}{|c|}{ Contribuição } \\
\hline & $\mathrm{KCl}$ & $\mathrm{CuCl}_{2}$ & $\Delta-\mathrm{Al}$ & Comp. org.* & Comp. org.** & $\mathrm{pH}$ \\
\hline & \multicolumn{4}{|c|}{$m_{c} \mathrm{~kg}_{\mathrm{c}} \mathrm{k}^{-1}$} & \multicolumn{2}{|c|}{ - } \\
\hline Testemunha & 16,90 & 43,29 & 26,39 & - & - & - \\
\hline Palha de cana & 14,29 & 40,92 & 26,63 & 0,24 & 9,3 & 90,74 \\
\hline Feijão de porco & 6,52 & 34,88 & 28,36 & 1,98 & 19,1 & 80,94 \\
\hline Esterco bovino & 11,35 & 37,75 & 26,40 & 0,02 & 0,3 & 99,72 \\
\hline Esterco de galinha & 0,38 & 21,83 & 21,44 & $-4,94$ & 00 & 100,0 \\
\hline Composto org. & 15,62 & 39,26 & 23,64 & $-2,75$ & 0 & 100,0 \\
\hline Vermicomposto & 3,42 & 30,63 & 27,21 & 0,82 & 6,1 & 93,90 \\
\hline Turfa & 16,28 & 42,33 & 26,05 & $-0,33$ & 0 & 100,0 \\
\hline Lodo 1 & 0,27 & 19,43 & 19,15 & $-7,23$ & 0 & 100,0 \\
\hline Lodo 2 & 0,23 & 20,30 & 20,06 & $-6,32$ & 0 & 100,0 \\
\hline Vinhaça & 0,70 & 21,80 & 21,10 & $-5,29$ & 0 & 100,0 \\
\hline
\end{tabular}

* Al em complexado orgânico;

Apenas o feijão de porco, a palha de cana, o vermicomposto e o esterco bovino apresentaram alguma contribuição do processo de complexação na redução dos teores de alumínio trocável do solo com a sua incorporação. Embora tenha-se observado contribuições consideráveis desse processo nos três primeiros materiais, fica evidente que o aumento do $\mathrm{pH}$ foi o principal responsável pela redução daquele atributo do solo. Apesar disso, vale a pena considerar que o feijão de porco foi o material que mais complexou o alumínio do solo, provavelmente devido aos ânions orgânicos originalmente presentes, ou mesmo formados durante sua decomposição.

Esses resultados permitem especular que, de maneira geral, o decréscimo de alumínio do solo, antes de ser o resultado de uma reação química de complexação, foi consequência do aumento do $\mathrm{pH}$ do meio, causado seja pela influência direta das características do material como turfa e lodos, ou ainda pela atividade microbiológica. 


\subsection{Experimento 2- Relação entre a degradação microbiana da matéria orgânica e o pH do solo.}

\subsubsection{Cinética da degradação dos materiais orgânicos}

Inicialmente serão discutidos os resultados obtidos para produção de $\mathrm{CO}_{2}$ nos primeiros 38 dias do experimento, durante os quais foram estudadas as temperaturas de incubação de 20 e $30^{\circ} \mathrm{C}$. Os valores obtidos nesse período foram ajustados ao modelo de cinética de primeira ordem, sendo os valores obtidos posteriormente sob $35^{\circ} \mathrm{C}$, reservados para discussão posterior.

Quando se utilizam compostos orgânicos com carbono marcado em trabalhos de respirometria, é possivel detectar apenas $0{ }^{14} \mathrm{CO}_{2}$ proveniente do material orgânico. Como para a grande maioria dos materiais orgânicos não se pode contar com este recurso, a única forma de se obter a quantidade de $\mathrm{CO}_{2}$ proveniente do material avaliado é deduzir a contribuição do carbono nativo do solo do total de $\mathrm{CO}_{2}$ produzido. Esta dedução é feita subtraindo-se a quantidade de $\mathrm{CO}_{2}$ produzida pela testemunha daquela que é liberada pelo tratamento com adição do material orgânico. Entretanto, sabe-se que a decomposição do carbono nativo pode ser estimulada (Hernandez et al., 1988) ou reprimida (Zilbilske, 1987) por ocasião da incorporação de outras fontes de carbono, resultando no que se denomina efeito primming. Essa é uma interferência que não pode ser contornada em experimentos de respirometria que não se utilizam de carbono marcado.

Como pode ser observado na Figura 6, o tratamento testemunha apresentou um desprendimento do $\mathrm{CO}_{2}$ de aproximadamente $600 \mathrm{mg}$, o qual pode ser considerado elevado quando comparado às quantidades líquidas produzidas por alguns tratamentos com adição de material orgânico.

Para todos os materiais orgânicos, após os primeiros 38 dias de incubação, a temperatura de $30^{\circ} \mathrm{C}$ promoveu maior desprendimento total de $\mathrm{CO}_{2}$ que a de $20^{\circ} \mathrm{C}$, observando-se em ambas as condições a seguinte ordem: vinhaça $>$ feijão de porco $>$ esterco bovino $>$ lodol $>$ turfa (Figura 6). 


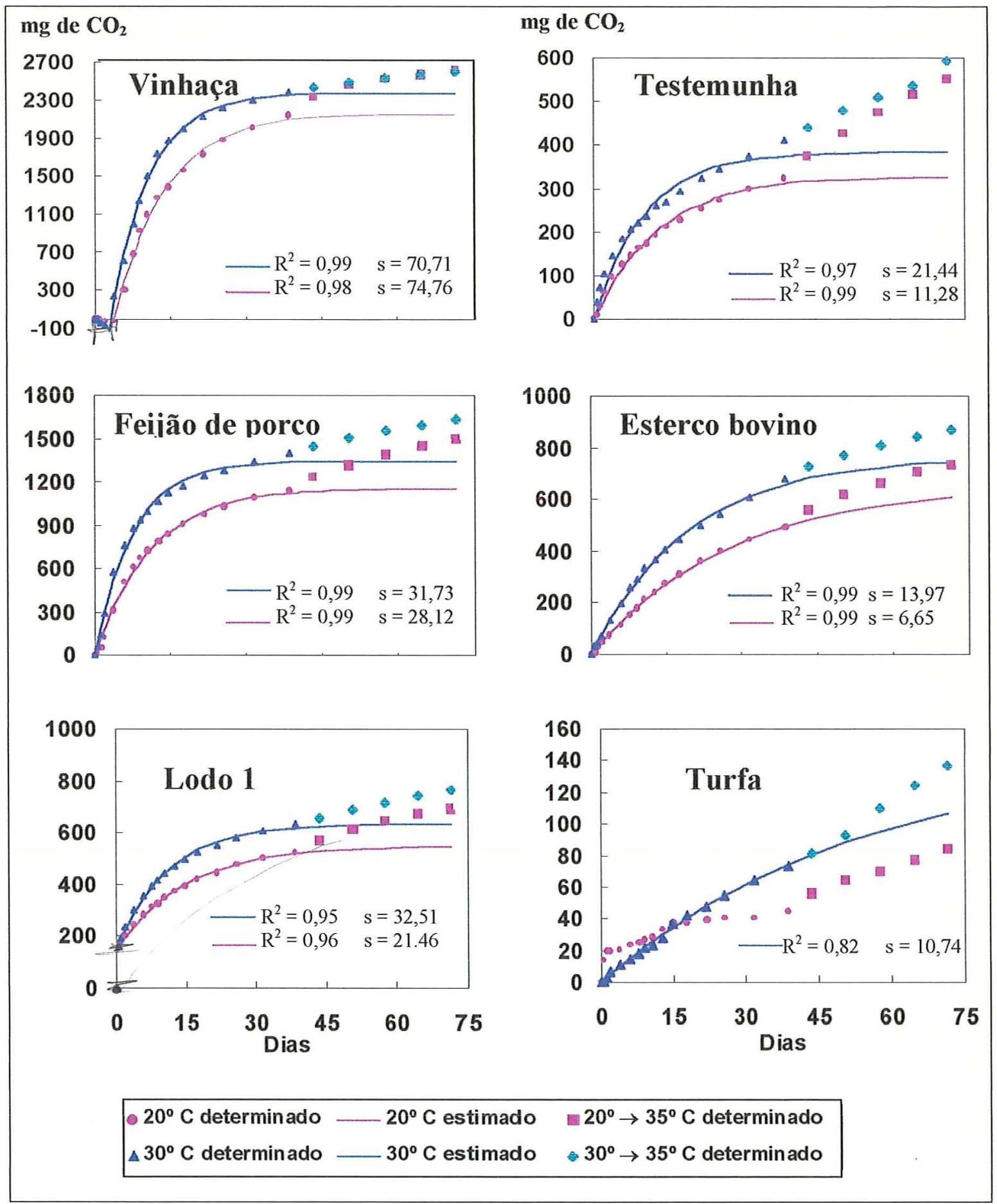

Figura 6. Quantidades acumuladas de $\mathrm{CO}_{2}$ liberadas pela testemunha e quantidades líquidas acumuladas liberadas pelos materiais estudados, em função do tempo de incubação. 
Esses resultados ressaltam a importância da temperatura na mineralização do carbono orgânico, que também pode ser constatada pelos dados obtidos por Joergensen et al. (1990), os quais observaram que após 240 dias de incubação, 6,4\% do carbono nativo de um solo foi mineralizado a $15^{\circ} \mathrm{C} ; 12,2 \%$ a $25^{\circ} \mathrm{C}$ e $35,4 \%$ a $35^{\circ} \mathrm{C}$.

Aos 38 dias de incubação as curvas de respirometria dos diferentes materiais, com exceção do esterco bovino e da turfa, já apresentavam uma tendência assintótica, evidenciando uma baixa velocidade de produção de $\mathrm{CO}_{2}$. O ajuste dos resultados de respirometria ao modelo de cinética de primeira ordem forneceram os parâmetros apresentados na Tabela 8 . De maneira geral, o modelo de cinética de primeira ordem se ajustou eficientemente aos dados experimentais conforme demonstrado pelos coeficientes de determinação obtidos e apresentados na Figura 6.

Tabela 8. Parâmetros da equação de cinética do primeiro grau ajustada as dados de liberação de $\mathrm{CO}_{2}$ pelos materiais orgânicos incubados a 20 e $30^{\circ} \mathrm{C}$

\begin{tabular}{|c|c|c|c|c|c|c|c|c|}
\hline & Material & Modelo & $\mathrm{a}$ & $\mathrm{p}$ & $\mathrm{b}$ & $\mathrm{k}$ & $t_{1 / 2}$ & $\begin{array}{c}\mathrm{C} \\
\text { respirado }\end{array}$ \\
\hline \multirow{7}{*}{$\begin{array}{l}0 \\
8 \\
8\end{array}$} & & & $-\cdots-m g C$ & $\mathrm{O}_{2} \cdots$ & dia & $\mathrm{dia}^{-1}$ & dia & $\%$ \\
\hline & Testemunha & $y=a\left(1-e^{-k x}\right)$ & 27,3 & - & - & 0,0754 & 9,2 & 2,2 \\
\hline & Feijão de porco & $y=a\left(1-e^{-k x}\right)$ & 154,8 & $-\infty$ & - & 0,0911 & 7,6 & 30,6 \\
\hline & Esterco bovino & $y=a\left(1-e^{-k x}\right)$ & 653,8 & - & - & 0,0362 & 19,1 & 10,8 \\
\hline & Vinhaça & $y=a\left[1-e^{-k(x-b)}\right]$ & 2156,3 & - & 3,85 & 0,0992 & 7,0 & 58,6 \\
\hline & Lodo 1 & $y=p+a\left(1-e^{-k x}\right)$ & 401,1 & 149,1 & - & 0,0665 & 10,4 & 14,2 \\
\hline & Turfa & não ajustado & - & -- & - & - & - & 1,2 \\
\hline \multirow{6}{*}{$\begin{array}{l}0 \\
8 \\
0\end{array}$} & Testemunha & $y=a\left(1-e^{-k x}\right)$ & 383,8 & - & - & 0,0972 & 7,1 & 2,7 \\
\hline & Feijão de porco & $y=a\left(1-e^{-k x}\right)$ & 1341,8 & - & - & 0,1326 & 5,2 & 38,1 \\
\hline & Esterco bovino & $y=a\left(1-e^{-k x}\right)$ & 762,5 & - & & 0,0516 & 13,4 & 18,5 \\
\hline & Vinhaça & $y=a\left[1-e^{-k(x-b)}\right]$ & 2374,4 & - & 3,17 & 0,1306 & 5,3 & 64,1 \\
\hline & Lodo 1 & $y=p+a\left(1-e^{-k x}\right)$ & 481,8 & 152,1 & - & 0,0893 & 7,8 & 13,2 \\
\hline & Turfa & $y=a\left(1-e^{-k x}\right)$ & 144,7 & - & - & 0,0186 & 37,3 & 2,0 \\
\hline \multicolumn{9}{|c|}{$\begin{array}{l}\mathrm{a}=\text { produção máxima de } \mathrm{CO}_{2} \\
\mathrm{~b}=\text { periodo necessário à adaptação microbiana; } \\
\mathrm{p}=\text { produção de } \mathrm{CO}_{2} \text { independente do tempo; } \\
\mathrm{k}=\text { constante de velocidade; } \\
\mathrm{t}_{1 / 2}=\text { meia vida. }\end{array}$} \\
\hline
\end{tabular}


Com relação ao feijão de porco e o esterco bovino, foram obtidos bons resultados com o ajuste do modelo básico de cinética de primeira ordem, em ambas temperaturas estudadas. Os parâmetros deste modelo para o feijão de porco evidenciam que tanto as quantidades de carbono liberadas na forma de $\mathrm{CO}_{2}$ como as constantes de velocidade foram relativamente elevadas. $O$ aumento na temperatura de incubação de 20 para $30^{\circ} \mathrm{C}$ promoveu um aumento de $45 \%$ na velocidade de degradação e de $24 \%$ na quantidade de $\mathrm{CO}_{2}$ desprendido.

O esterco bovino se degradou com velocidade relativamente baixa, tanto a 20 como a $30^{\circ} \mathrm{C}$, liberando menos de $20 \%$ do seu carbono orgânico na forma de $\mathrm{CO}_{2}$. É interessante observar, que estes valores de porcentagem de degradação são similares aos obtidos para o lodo, embora o carbono orgânico deste último tenha se degradado mais rapidamente que o do esterco bovino, com acréscimos de velocidade de $84 \%$ e $73 \%$ a 20 e a $30^{\circ} \mathrm{C}$, respectivamente.

O ajuste do modelo de cinética de primeira ordem aos dados de respirometria do lodo de esgoto mostrou uma característica especial. Este material provocou uma liberação de aproximadamente $150 \mathrm{mg}$ de $\mathrm{CO}_{2}$ já nas primeiras 12 horas de incubação, o que provavelmente pode ser atribuído à reação química praticamente instantânea entre íns carbonato do material com os componentes da acidez do Cambissolo. A solução encontrada para ajustar o modelo de cinética de primeira ordem a tal comportamento foi introduzir um novo parâmetro $p$ à equação do modelo básico, para representar uma liberação de $\mathrm{CO}_{2}$ independente do tempo de incubação. É importante notar que a condução da incubação a 20 ou $30^{\circ} \mathrm{C}$ não afetou a magnitude deste parâmetro, parecendo comprovar a natureza puramente química dessa emanação inicial de $\mathrm{CO}_{2}$. Por outro lado, a citada variação de temperatura promoveu um aumento de $34 \%$ na velocidade de produção de $\mathrm{CO}_{2}$ na sequência da incubação. Vale ressaltar que a inclusão do $\mathrm{CO}_{2}$ produzido por uma reação inorgânica introduz erro nos ensaios de respirometria.

Outro material que apresentou comportamento peculiar durante a incubação foi a vinhaça. No início da degradação desse resíduo são observados valores negativos para a produção líquida de $\mathrm{CO}_{2}$ nas duas temperaturas estudadas. Como os pontos do gráfico resultam da diferença entre a produção de $\mathrm{CO}_{2}$ do tratamento e da testemunha, os 
dados negativos apenas indicam que no tratamento com vinhaça ocorreu menor liberação de $\mathrm{CO}_{2}$ que no tratamento testemunha durante os primeiros dias de incubação, como pode ser observado na Figura 7. Isso evidencia a ocorrência de um período de adaptação da população microbiana do solo provocado por um provável impacto da incorporação do material orgânico. Em geral, a adição de vinhaça ao solo promove alterações significativas na população microbiana, conforme foi comprovado por Camargo (1954). Este período é denominado lag-fase, o qual embora esteja sempre presente nos processos de degradação, nem sempre pode ser claramente identificável em função da periodicidade das medidas de $\mathrm{CO}_{2}$. Quando se manifesta, pode ser identificado através de uma tendência sigmóide da curva de respirometria (Figura 7).

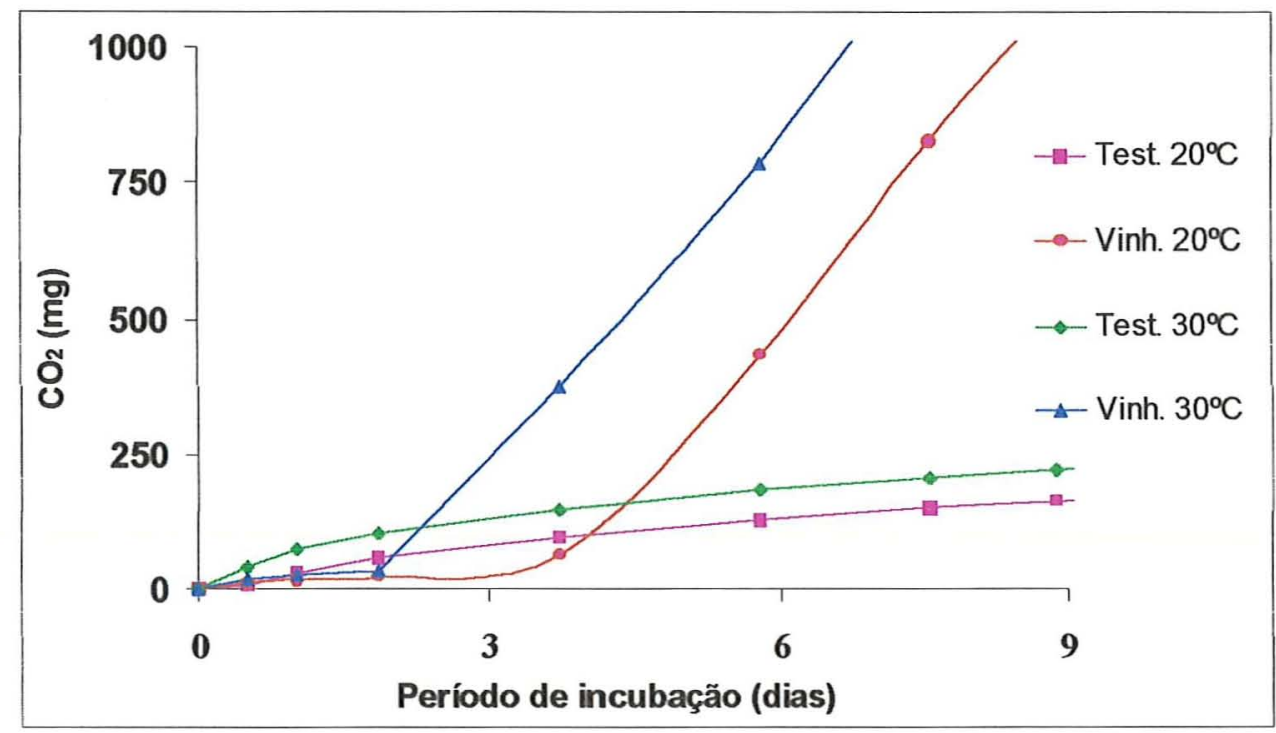

Figura 7. Curvas de $\mathrm{CO}_{2}$ acumulado do tratamento testemunha e de $\mathrm{CO}_{2}$ acumulado bruto da vinhaça, para as temperaturas de 20 e $30^{\circ} \mathrm{C}$.

No estudo da cinética de degradação da vinhaça utilizou-se do recurso de não incluir os valores de produção líquida negativa de $\mathrm{CO}_{2}$. $\mathrm{O}$ modelo básico de cinética de primeira ordem foi modificado pela introdução de um novo parâmetro, $\boldsymbol{b}$, que se soma ao período de incubação em dias $\boldsymbol{t}$. Esse parâmetro $\boldsymbol{b}$ representa, em suma, o período necessário para ultrapassar a adaptação inicial e dar sequência à degradação do material. 
A vinhaça foi o material que teve seu conteúdo em carbono orgânico degradado de forma mais completa e com maior velocidade. A $30^{\circ} \mathrm{C}$ cerca de $64 \%$ do carbono orgânico presente no resíduo foi transformado em $\mathrm{CO}_{2}$. $\mathrm{O}$ aumento de temperatura de incubação de 20 para $30^{\circ} \mathrm{C}$, promoveu um aumento de $32 \%$ na velocidade de degradação e de apenas $9 \%$ na quantidade de carbono transformado em $\mathrm{CO}_{2}$. Observa-se que a decomposição da fração orgânica da vinhaça foi menos afetada pela temperatura que a dos demais materiais, o que pode ser explicado pelo fato da vinhaça conter formas de carbono facilmente decomponíveis (Rodella et al., 1983).

A turfa foi o material menos degradado durante o periodo de incubação, por ser o resultado final de um processo de decomposição de material orgânico. As quantidades individuais de $\mathrm{CO}_{2}$ produzidas nos intervalos de medida muitas vezes se confundiram com os da testemunha, principalmente a $20^{\circ} \mathrm{C}$, causando menor exatidão na estimativa da quantidade líquida de $\mathrm{CO}_{2}$ liberada do solo. Assim sendo, adaptou-se o modelo de cinética de primeira ordem apenas aos dados de incubação da turfa a $30^{\circ} \mathrm{C}$, para o qual a constante de velocidade foi bastante pequena, com cerca de um quinto da velocidade do carbono nativo do solo.

Utilizando-se as constantes de velocidade de primeira ordem de cada material estudado, foram calculados seus respectivos valores de meia-vida $\left(t_{1 / 2}\right)$, os quais representam o tempo em dias necessário à degradação da metade do carbono orgânico liberado como $\mathrm{CO}_{2}$ no período de estudo (Tabela 8). Por também se tratar de uma parâmetro que avalia a velocidade de degradação dos materiais, a interpretação de seus valores é feita de forma igual a da constante de velocidade $\boldsymbol{k}$.

Serão considerados a seguir o comportamento das curvas de respirometria após os primeiros 38 dias de incubação, quando tanto os tratamentos que vinham sendo conduzidos a 20 como a $30^{\circ} \mathrm{C}$ tiveram a temperatura de incubação elevada para $35^{\circ} \mathrm{C}$.

De maneira geral, a elevação das temperaturas de incubação para $35^{\circ} \mathrm{C}$, incrementou a produção de $\mathrm{CO}_{2}$, como pode ser constatado na Figura 6 , pela mudança do comportamento dos pontos experimentais após o $38^{\circ}$ dia de incubação, em relação à curva ajustada aos dados obtidos até aquele período. 
As curvas de produção de $\mathrm{CO}_{2}$ acumulado referentes ao esterco bovino mantiveram-se praticamente paralelas, enquanto que para o lodol e o feijão de porco observou-se um ligeira tendência de aproximação das mesmas.

O efeito mais interessante ocorreu em relação a vinhaça, pois após o referido aumento das temperaturas, a produção de $\mathrm{CO}_{2}$ da vinhaça que vinha sendo incubada a $20^{\circ} \mathrm{C}$ foi especialmente incrementada, contrastando com o que ocorreu no processo conduzido a $30^{\circ} \mathrm{C}$, em que a liberação de $\mathrm{CO}_{2}$ pouco se alterou. Como consequência, as respectivas curvas de produção de $\mathrm{CO}_{2}$ se juntaram em uma única curva a partir do $50^{\circ}$ dia de incubação.

Esse resultado evidencia que na incubação da vinhaça a $30^{\circ} \mathrm{C}$ a maior parte do seu conteúdo de carbono orgânico já tinha sido transformado, boa parte dele em $\mathrm{CO}_{2}$ e o restante possivelmente incorporado à biomassa. É bastante provável que aos 71 dias de incubação o processo de transformação dos compostos orgânicos originalmente presentes na vinhaça estivesse completo.

Com base nessa análise parece claro que nos demais materiais o processo de transformação dos compostos orgânicos presentes ainda estava longe de ser completo.

\subsubsection{Relação entre produção de $\mathrm{CO}_{2}$ e pH do solo}

Durante o processo de incubação discutido no item 4.2.1, paralelamente às medidas de $\mathrm{CO}_{2}$, foram determinados os valores de $\mathrm{pH}$ do solo em solução de $\mathrm{CaCl}_{2}$ $0,01 \mathrm{~mol} \mathrm{~L}^{-1}$, os quais são apresentados na Figura 8 como a diferença entre o valor de $\mathrm{pH}$ do tratamento $\mathrm{e} o \mathrm{pH}$ da testemunha em cada época de amostragem.

De modo geral, as variações de $\mathrm{pH}$ em relação à testemunha causadas pela adição de material orgânico ao solo tiveram comportamento similar nas temperaturas de incubação 20 e $30^{\circ} \mathrm{C}$, conforme pode se observar pelas curvas exibidas na Figura 8 . Pode-se constatar também, que a elevação das temperaturas de incubação para $35^{\circ} \mathrm{C}$, aos 38 dias, não alterou a tendência que vinha sendo observada. 


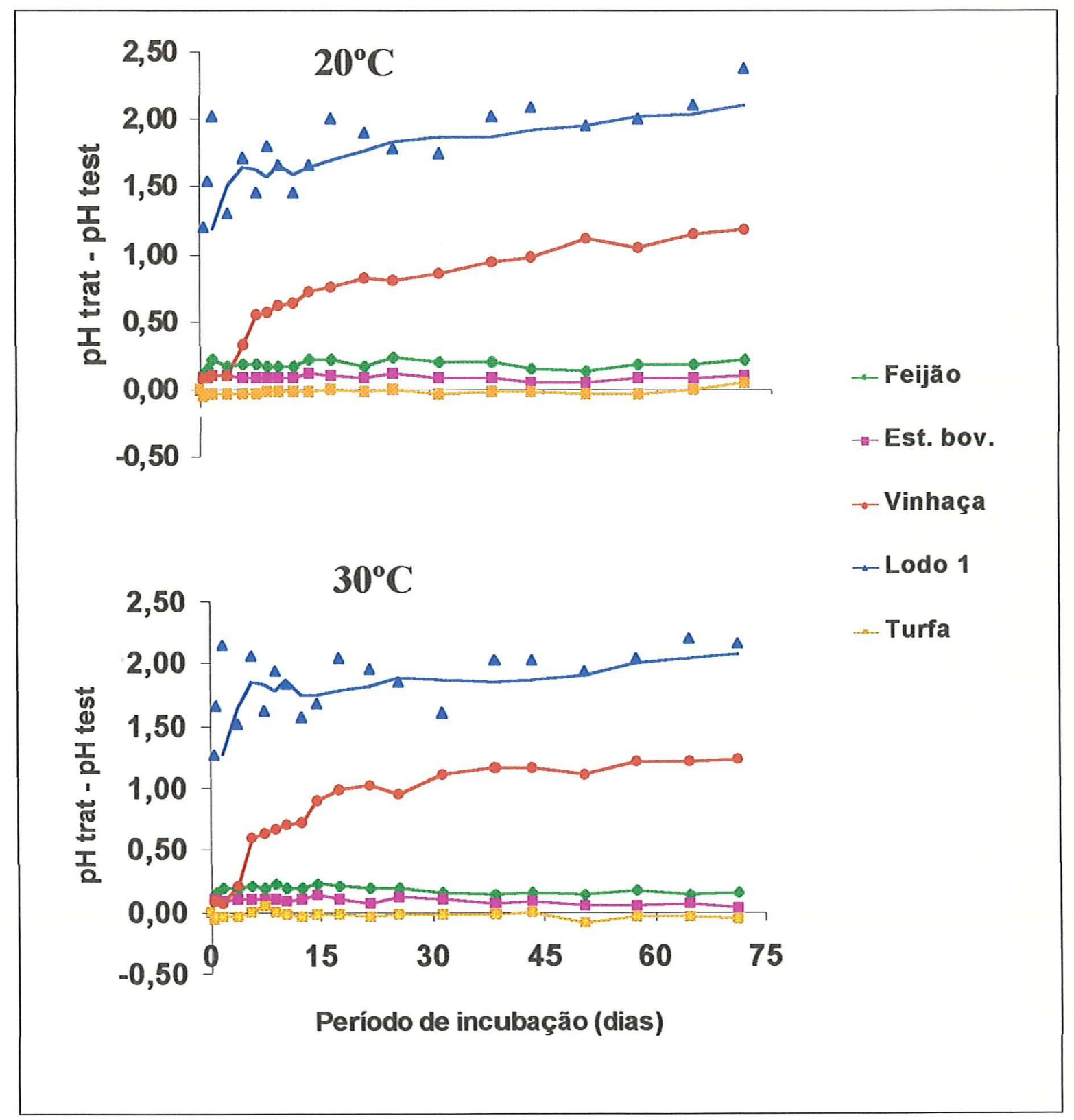

Figura 8. Diferença entre os valores de $\mathrm{pH}$ dos tratamentos com incubação de material orgânico e o tratamento testemunha, em função do período de incubação, para as temperaturas de 20 e $30^{\circ} \mathrm{C}$. 
Os materiais orgânicos, com exceção da turfa, promoveram elevação significativa do $\mathrm{pH}\left(\mathrm{CaCl}_{2}\right)$ do solo já no primeiro dia de incubação (Apêndice 4). $\mathrm{O}$ feijão de porco e o esterco bovino mantiveram a diferença de $\mathrm{pH}\left(\mathrm{CaCl}_{2}\right)$, em relação a testemunha, praticamente constante até a última avaliação, enquanto que para a vinhaça esta diferença aumentou progressivamente ao longo do período de incubação, conforme se observa na Figura 8.

No tratamento com vinhaça observou-se também, que a temperatura de $30^{\circ} \mathrm{C}$ proporcionou valores de $\mathrm{pH}\left(\mathrm{CaCl}_{2}\right)$ significativamente maiores que a $20^{\circ} \mathrm{C}$, na maior parte dos épocas de amostragem. (Apêndice 4). Esse comportamento é uma evidência do efeito da atividade microbiana na velocidade de alteração do $\mathrm{pH}$ do solo.

A turfa, por sua vez, apresentou um ligeira tendência de diminuição do $\mathrm{pH}\left(\mathrm{CaCl}_{2}\right)$ do solo, apesar dos valores deste atributo não terem diferido estatisticamente dos obtidos na testemunha, para a maioria das épocas de amostragem (Apêndice 4).

$\mathrm{O}$ lodo foi o material que resultou nas maiores diferenças de $\mathrm{pH}$, levando o $\mathrm{pH}$ $\left(\mathrm{CaCl}_{2}\right)$ do solo a valores próximos a 6,5 , resultando também em maiores flutuações nos resultados experimentais. Observou-se que o efeito do lodo sobre o $\mathrm{pH}$ também foi afetado pela temperatura, sendo que maiores valores de $\mathrm{pH}$ foram observados a $30^{\circ} \mathrm{C}$ na maioria das épocas de amostragem, provavelmente devido ao estímulo do aumento de temperatura sobre a reação entre o material e os componentes da acidez do solo.

$\mathrm{O}$ objetivo principal desse experimento foi correlacionar as alterações no $\mathrm{pH}$ do solo, promovidas pela adição de matéria orgânica, com a respectivas quantidades de $\mathrm{CO}_{2}$ produzidas pela respiração dos microrganismos. Conforme discutido anteriormente, para a maioria dos materiais orgânicos incubados, o acréscimo inicial no $\mathrm{pH}$ manteve-se constante ao longo da incubação. A vinhaça apresentou comportamento contrário ao dos demais, e por esse motivo apenas para este material, foi possivel relacionar as suas quantidades de $\mathrm{CO}_{2}$ acumuladas com os respectivos valores no $\mathrm{pH}$ do solo ao longo do período de incubação, tanto a $20^{\circ} \mathrm{C}$ como a $30^{\circ} \mathrm{C}$, conforme mostrado graficamente na Figura 9. 


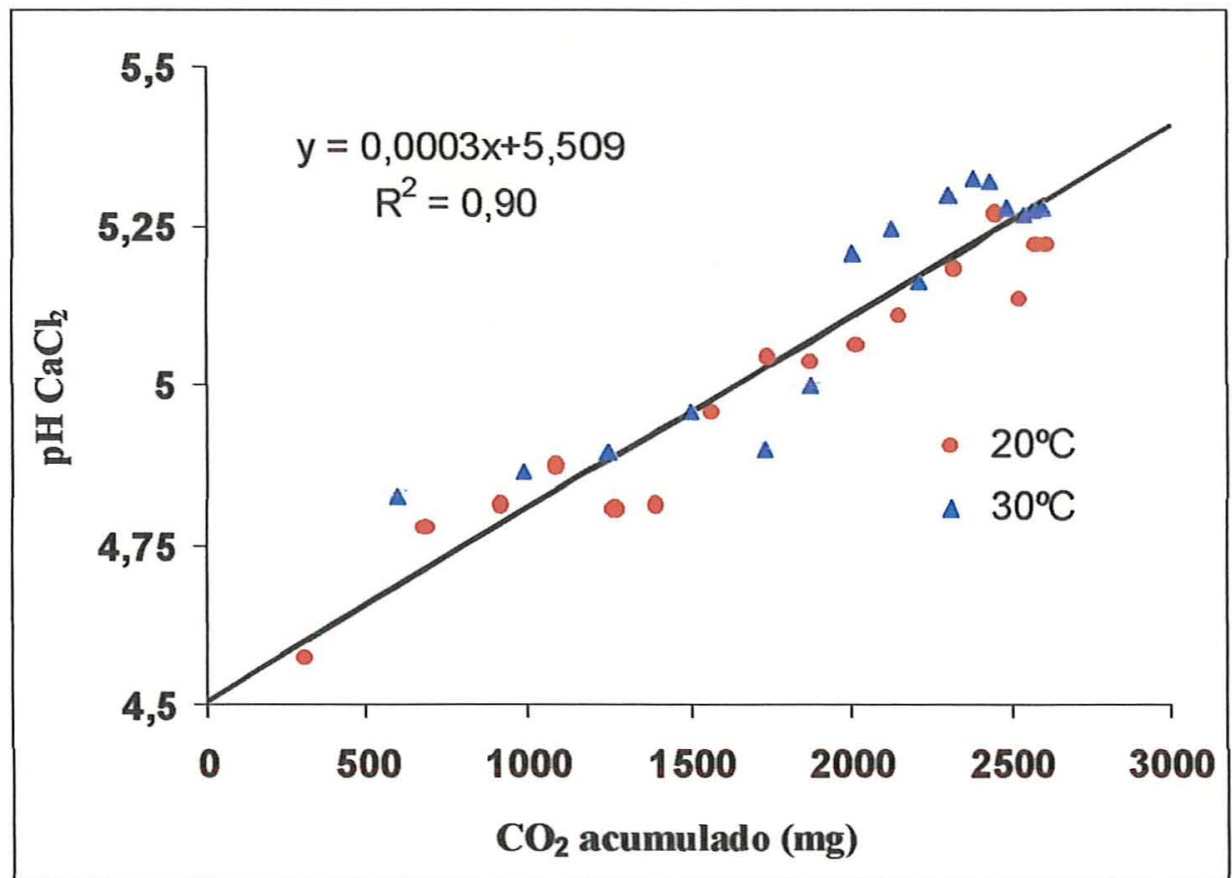

Figura 9. Relação entre as quantidades acumuladas de $\mathrm{CO}_{2}$ liberado pela vinhaça no decorrer do período de incubação e os respectivos valores de $\mathrm{pH}$ em $\mathrm{CaCl}_{2}$.

Parece evidente, portanto, que a elevação do $\mathrm{pH}$ para os tratamentos com aplicação de vinhaça, a 20 ou $30^{\circ} \mathrm{C}$, está diretamente relacionada à atividade microbiana, expressa através da produção de $\mathrm{CO}_{2}$.

Como era de se esperar, as alterações de $\mathrm{pH}$ do solo se relacionaram ao teor de alumínio trocável do solo, conforme comprovado aos 38 dias de incubação A relação entre estes atributos pode ser observada na Figura 10. 


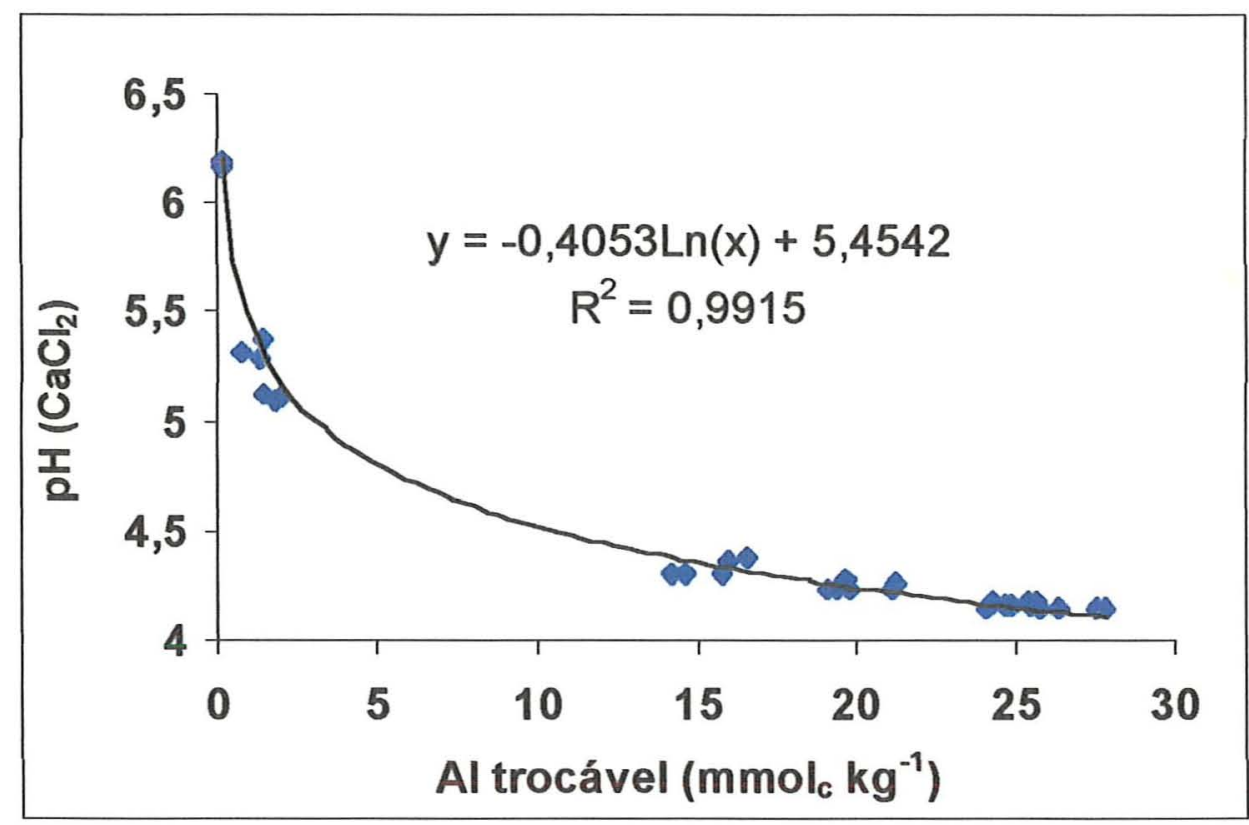

Figura 10. Relação entre de pH e alumínio trocável do solo após 38 dias de incubação com diversas fontes de carbono orgânico.

Portanto, ficou claro que o estímulo da atividade microbiana do solo proporcionado pela a vinhaça resultou em elevação de $\mathrm{pH}$, a qual, por sua vez, teve como consequência o decréscimo no teor de alumínio trocável do solo. 


\section{CONCLUSÕES}

- Materiais orgânicos como a vinhaça, que não contém componentes alcalinos inorgânicos e cujo carbono é de fácil decomposição no solo, afetam a acidez do mesmo pelo estímulo à atividade microbiana que promovem;

- A redução dos teores de alumínio trocável do solo em função da incubação de materiais orgânicos foi mais influenciada pelo aumento de $\mathrm{pH}$ que pelo processo de complexação do alumínio do solo;

- A redução da acidez solo pela adição de materiais orgânicos, como os lodos de esgoto e o esterco de galinha, que contém bases inorgânicas é determinada pela ação dessas espécies químicas, independentemente da natureza e das transformações da fração orgânica destes materiais.

- Em trabalhos de respirometria que se utilizam materiais orgânicos contendo carbonato, a contabilização do $\mathrm{CO}_{2}$ proveniente da reação deste íon com a acidez do solo, como respiração microbiana, pode levar a erros na caracterização da biodegradabilidade destes materiais. 


\section{REFERÊNCIAS BIBLIOGRÁFICAS}

ALCARDE, J.C. Corretivos da acidez dos solos: características e quantidade. In. SEMINÁRIO SOBRE CORRETIVOS AGRÍCOLAS, Piracicaba, 1985. Resumos. Piracicaba: Fundação Cargill, 1985 p. 97-119.

ALEXANDER, M.; SCOW, M. Kinetics of biodegradation in soil In: SAWHNEY, B.L.; BROWN, N. (Ed.) Reaction and movement of organic chemicals in soils. Madison: Soil Science Society of America; America Society of Agronomy, 1989 cap. 10. p. 243-269.

ALEXANDER, M.I.H. Introduction to soil microbiology. 4. ed. New York: John Wiley, 1967. $472 \mathrm{p}$.

ANDERSON, T.H. \& JOERGENSEN, R.G. Relationship between SIR and FE estimates of microbial biomass in deciduous forest soils at different $\mathrm{pH}$. Soil Biology \& Biochemistry, v.29, n.7, p. 1033-1042, 1997.

BARTHA, R; PRAMER, D. Features of a flask and a method for measuring the persistence and biological affects of pesticides in soil. Soil Science, v. 100, n.1, p.68$70,1965$.

BARTLETT, R.J.; RIEGO, D.C. Effects of chelation on the toxicity of aluminum. Plant and Soil, v.37, p.419-423, 1972.

BATES, R.G. Determination of pH: Theory and practice. 2. ed. New York: John Wiley, 1973. 332p.

BERNAL, M.P.; NAVARRO, A.F.; ROIG, A.; CEGARRA, J.; GARCIA, D. Carbon and nitrogen transformations during composting of sweet sorghum bagasse. Biology and Fertility of Soils, v.22, p.141-148, 1996. 
BOWER, C.A.; HARPER, W.G.; MOODIE, C.D.; OVERSTREET, R.; RICHARDS, L.A. Apparatus for studying biochemical transformation in incubated soil. Soil Science Society of America Proceedings, v.22, n.3, p.270-271, 1958.

BRASIL. Ministério da Agricultura. Secretaria Nacional de Defesa Agropecuária. Análise de corretivos, fertilizantes e inoculantes. Brasilia, 1988. 104p.

BRENES, E.; PEARSON, R.W. Root responses of three gramineae species to soil acidity in an Oxisol and an Ultisol. Soil Science, v.116, p.295-302, 1973.

CAMARGO, O.A. de; VALADARES, J.M.A. S.; BERTON, R.S.;EÓFILO SOBRINHO, J.; MENK, J.R.F. Alterações de características químicas de um Latossolo Vermelho Escuro pela aplicação de vinhaça. Campinas: IAC, 1987. 23p. (IAC. Boletim Cientifico, 9).

CAMARGO, $R$ de $O$ desenvolvimento da flora microbiana nos solo tratados com vinhaça. Piracicaba: ESALQ, Instituto Zimotécnico, p. 1-44, 1954. (IZ. Boletim 9).

CAMBUIM, F.A.; CORDEIRO, D.A. Ação de vinhaça sobre $\mathrm{pH}$, acidez total e acumulação de nutrientes, em solo arenoso. STAB. Açúcar, Álcool e Subprodutos, v. 4, n. 4 , p. $23-30,1986$.

CERRI, C.C.; ANDREUX, F.; EDUARDO, B.M.; CHONE, T.; PICCOLO, M.C. Incubador para estudos sobre decomposição de material orgânico no solo. Revista Brasileira de Ciência do Solo, v. 18, n.2, p. 1-5, 1994.

CHAPMAN, H.D.; OXLEY, J.H.; CURTIS, J.H. The determination of $\mathrm{pH}$ at soil moisture contents approximating field conditions. Soil Science Society of America Proceedings, v.5, p. $191-200,1941$ 
CLARK, J.S.; NICHOL, W.E. The lime potential, percent base saturation acid surface horizons of mineral and organic soils. Canadian Journal of Soil Science, v. 46, p. $281-285,1966$.

EIRA , A.F.; CARVALHO, P.C.T. A decomposição da matéria orgânica pelos microrganismos do solo e sua influência nas variações do $\mathrm{pH}$. Revista de Agricultura, v.45, p.15-21, 1970.

ERNANI, P.R.; GIANELLO, C. Diminuição do alumínio trocável do solo pela incorporação de esterco de bovino e camas de aviário. Revista Brasileira de Ciência do Solo, v.7, p.161-165, 1983.

FASSBENDER, H.W. Química de suelos: com énfasis en suelos de América Latina. Costa Rica; Turrialba: IICA, 1975. 385p.

FINE, P.; MINGELGRIN, U.; FEIGIN, A. Incubation studies of the fate of organic nitrogen in soils amended with activated sludge. Soil Science Society of America Journal, v.53, n.2, p. 444-450, 1989.

GRISI, B.M. Metodologia de determinação de biomassa microbiana de solo. Revista Brasileira de Ciência do Solo, v.8, n.2, p.167-172, 1984.

HADAS, A.; PORNOY, R. Nitrogen and carbon mineralization rates of composted manures incubation in soil. Journal of Environmental Quality, v.23, n.6, p.1184$1189,1994$.

HERNANDEZ, T; GARCIA, C.; LAX, A.; CEGARRA, J.; ROIG, A.; MORENO, J.I. Transformation of carbon and nitrogen in a Calciorthid soil amended with a range of organic residues. Plant and Soil, v.105, n.2, p. 205-211, 1988. 
HOYT, P.B.; TURNER, R.C. Effects of organic materials added to very acid soils, on $\mathrm{pH}$, aluminum, exchangeable $\mathrm{NH}_{4}$, and crop yield. Soil Science, v.119, p.227-237, 1975.

HUE, N.V.; CRADDOCK, G.R; ADANS, F. Effects of organic acids on aluminum toxicity in subsoils. Soil Science Society of America Journal, v.50, p.28-34, 1986.

JENKINSON D.S.; RAYNER, J.H. The turnover of soil organic matter in some of the Rothamsted Classical Experiments. Soil Science, v. 123, p. 298-305, 1977.

JOERGENSEN,R.G.; BROOKES, P.C; JENKINSON, D.S. Survival of the soil microbial biomass at elevated temperatures. Soil Biology and Biochemistry, v.22, n. 8, p. $1129-1136,1990$.

JUO, A.S.R.; KAMPRATH, J. Copper chloride as an estractant for estimating the potentially reactive aluminum pool in acid soil. Soil Science Society of American Journal, Madison, v.43, p.35-38, 1979.

KORCAK, R.F. Effeets of applied sewage sludge compost and fluidizedbed material on apple seedling growth. Communications in Soil Science and Plant Analysis, v. 11, p.571-585, 1980 .

LATHAN, J.L. Cinética elementar de reação. São Paulo: Edgard Blucher; EDUSP, $1974.113 \mathrm{p}$.

LEAL, J.R; AMARAL SOBRINHO, N.M.B.; VELLOSO, A.C.X.; ROSSIELLO, R.O.P. Potencial redox e pH: variações em um solo tratado com vinhaça. Revista Brasileira de Ciência do Solo, v.7, n.3 p.257-261, 1983. 
LIN, C.; COLEMAN, N.T. The measurement of exchangeable aluminum in soil and clays. Soil Science Society of American Proceedings, v.24, p.444 446, 1960.

MALAVOLTA, E. Reação do solo e crescimento das plantas. In: SEMINÁRIO SOBRE CORRETIVOS AGRÍCOLAS, Campinas, 1985. Resumos. Campinas: Fundação Cargill, 1985. p. 3-64.

MALAVOLTA, E; KLIEMANN, H.J. Desordens nutricionais no cerrado. Piracicaba: Associação Brasileira para Pesquisa da Potassa e do Fosfato, 1985. 136 p.

MATTIAZZO, M.E; GLORIA, N.A. Effect of vinasse on soil acidity Water Science and Technology, v.19, p.1293-1296, 1987.

MAZUR, N.; VELLOSO, A.C.X; SANTOS, G.A. Efeito do composto de resíduo urbano no pH e alumínio trocável em solo ácido. Revista Brasileira de Ciência do Solo, v.7, p.157-159, 1983.

McLEAN, E. Chemistry of soil aluminum. Soil Science and Plant Analysis, v.7, n.7, p.619-636, 1976.

MENDONÇA, E.S. Oxidação da matéria orgânica e sua relação com diferentes formas de aluminio de Latossolos. Revista Brasileira de Ciência do Solo, v.19, p.25-30, 1995.

MELLO, F. A.F. de; FREIRE, F.M; CASAGRANDE, J.C.; CHITOLINA, J.C.; PEDRAS, J.F.; STOLF, R. Efeitos da incorporação de "capim carrapicho" Cenchrus echinatus $(\mathrm{L}$.$) , sobre o \mathrm{pH}, \mathrm{H}^{+}, \mathrm{Al}^{3+}$ e capacidade de retenção de umidade de solos do município de Piracicaba. Revista de Agricultura, v.57, n.3, p.193-202, 1982. 
MELLO, F. A.F. de Origem, natureza e componentes da acidez do solo: critério para calagem. Seminário sobre corretivos agrícolas. Campinas: Fundação Cargill, 1985. cap. 2. p. 67-92.

MINHONI, M.T.A.; EIRA, A.F.; CARDOSO, A.J.B.N. Efeitos da adição de N e P sobre a decomposição de diferentes tipos de material orgânico no solo. Revista Brasileira de Ciência do Solo, v.14, n.3, p.297-304, 1990.

MIYAZAWA, M.; PAVAN, M.A.; CALEGARI, A. Efeito de material vegetal na acidez do solo. Revista Brasileira de Ciência do Solo, v.17, p.411-416, 1993.

MORRILL, L.G.; MAHILUM, B.C.; MOHIUDIN,S.H. Organics compounds in soil: sorption, degradation end persistence. Michigan: Ann Arbor Science, 1982. 157p.

NAGANAWA, T; KYUMA, K.; YAMAMOTO, Y.; YOKOI, H.; TATSUYAMA, K. Measurement of soil respiration in the field: Influence of temperature, moisture level and application of sewage sludge compost and agro-chemicals. Soil Science and Plant Nutrition, v.35, n.4, p.509-516, 1989.

PARR, J.F. Chemical and biological considerations for land applications of agricutural land municipal wastes In: FAO. Organic materials as fertilizers. Rome, 1975. p. 227-251. (FAO. Soils Bulletin, 27).

PAUL, E.A. Dynamics of organic matter in soil. Plant and Soil, v. 76, p. 257-285, 1984.

PAVAN, M.A. Alumínio em solos ácidos do Paraná: relação entre o alumínio não trocável e solúvel, com $\mathrm{pH}, \mathrm{CTC}$, porcentagem de saturação de $\mathrm{Al}$ e matéria orgânica. Revista Brasileira de Ciência do Solo, v.7, p. 39-46, 1983. 
PAVAN, M.A.; BIGHAN, F.T; PRATT, P.F. Toxicity of aluminum to coffee in Ultisols and Oxisols amended with $\mathrm{CaCO}_{3}, \mathrm{MgCO}_{3}$ and $\mathrm{CaSO}_{4} \cdot 2 \mathrm{H}_{2} \mathrm{O}$. Soil Science Society of America Journal, v.46, p. 1201-1207, 1982.

PAZ, L.G; PEDRosA, A.C.; LOBÃO, A.O; CARDOSO, E.G.; SUZUKI, J; SLEUTJES, M.A.; L. FILHO, S.A. de; MELLO, F. A.F. de Efeitos da aplicação da torta de mamona sobre algumas propriedades químicas de um Latossolo roxo e de um Regossol. Revista de Agricultura, v.51, n.3, p.207-213, 1976.

PEECH, M. Hydrogen-ion activity. In: BLACK, C.A. (Ed.) Methods of soil analysis: part 2: Chemical and microbiological properties. Madison: American Society of Agronomy, 1965. cap. 60, p. 914-925.

PIERRE, W.H.; BANWART, W.L. Excess base and excess base/nitrogen ratios of various crop species and plant parts. Agronomy Journal, v. 65, p-91-96, 1975.

PIONKE, H.B.; COREY, R.B. Relations between acidic aluminum and soil pH, clay, and organic mater. Soil Science Society America Proceedings, v.31, p.749-752, 1967.

PRITCHARD, D.T. Spectrophotometric determination of aluminum is soil extracts with xilenol orange. Analyst, v. 92, p. $103-106$, Feb., 1967.

RAGLAND, J.L.; COLEMAN, N.T. The hydrolysis of aluminum salts in clay and soil systems. Soil Science Society of America Proceedings, v.98, p. 100-106, 1960.

RAIJ, B. van. Propriedades eletroquímicas de solos. In: Simpósio avançado de química e fertilidade do solo., Piracicaba, 1986. Anais. Campinas: Fundação Cargill, p. 9-39. 
RODELLA, A.A. Métodos de avaliação de materiais orgânicos e efeitos de sua incorporação ao solo sobre a mobilização de macronutrientes. Piracicaba, 1996. 148p. Tese (Livre Docência - Escola Superior de Agricultura "Luiz de Queiroz", Universidade de São Paulo).

RODELLA, A.A.; FERRARI, S.E. A utilização da vinhaça e efeitos de sua aplicação como fertilizantes na cana-de-açúcar. Brasil Açucareiro, v.90, n.7, p.6-13, 1977.

RODELLA, A.A; ZAMBELLO JUNIOR, E; ORLANDO FILHO, E. Effects of vinasse added to soil on $\mathrm{pH}$ and exchangeable aluminum content. In. CONGRESS OF INTERNATIONAL SOCIETY OF SUGAR CANE TECHNOLOGISTS, 17 , Havana, 1983. Proceedings. Havana: José Marti, 1983. v.1, p.237-245.

RODELLA, A.A; ALCARDE, J.C Avaliação de materiais orgânicos empregados como fertilizantes. Scientia Agrícola, v.51, n.3, p. 556-562, 1994.

ROIG, A. ; LAX, A.; CEGARRA, J.; COSTA, F; HERNADEZ, M.T. Cation exchange capacity as a parameter for measuring the humification degree of manures. Soil Science, v.146, n.5, p.311-316, 1988.

SENGIK, E.; RIBEIRO, A.C.; CONDÉ, A.R. Efeito da vinhaça em algumas propriedades de amostras de dois solos de Viçosa (MG). Revista Brasileira de Ciência do Solo, v.12, p. 11-15, 1988.

SCHOFIELD, R.K; TAYLOR, A.W. The measurement of soil pH. Soil Science Society America Proceedings, v. 19, p. 164-167, 1955.

SMITH,S.R; HADLAY, P. Carbon and nitrogen mineralization characteristics of organics fertilizers in a soil-less incubation system. Fertilizer Research, v.23, n.2, p.97-103, 1990. 
SPARLING, G.P. Ratio of microbial biomass carbon to soil organic carbon as a sensitive indicator of changes in soil organic matter. Australian Journal of Soil Research, v.30, p.195-207, 1992.

TAKACHI, C.Y.; PAVAN, M.A. Efeito da natureza e da força iônica do cátion na acidez da solução do solo. Revista Brasileira de Ciência do Solo, v. 19, p.15-18, 1995 .

TESTER, C.F. Organic amendment effects on physical and chemical properties of a sandy soil. Soil Science Society of America Journal, v.54, n.3, p. 827-831, 1990.

THOMAS, G.W. Soil pH and soil acidity. In: SPARKS, D.L. (Ed.) Methods of soil analysis: part 3: Chemical methods. Madison: Soil Science Society of America; American Society of Agronomy, 1996. cap. 16. p. 475-490.

VELOSO, C.A.C.; BORGES, A.L; MUNIZ, A.S.; VEIGAS, I.A. de J.M. Efeito de diferentes materiais no pH do solo. Scientia Agrícola, v. 49, n.1, p. 123-128, 1992.

YADVINDER-SINGH, BIJAY-SINGH; KHIND, C.S. Nutrient transformations in soils amended with green manures. Advances in Soil Science, v.20, p. 238-309, 1992.

YAN, F; SCHUBERT, S; MENGEL, K Soil pH changes during legume growth and application of plant material. Biology and Fertility of Soils, v.23, n.3, p.236-242, 1996.

ZILBILSKE, L.M. Dynamics of nitrogen and carbon in soil during papermill sludge decomposition. Soil Science, v.143, n.1, p. 26-33, 1987. 
APÊNDICE 


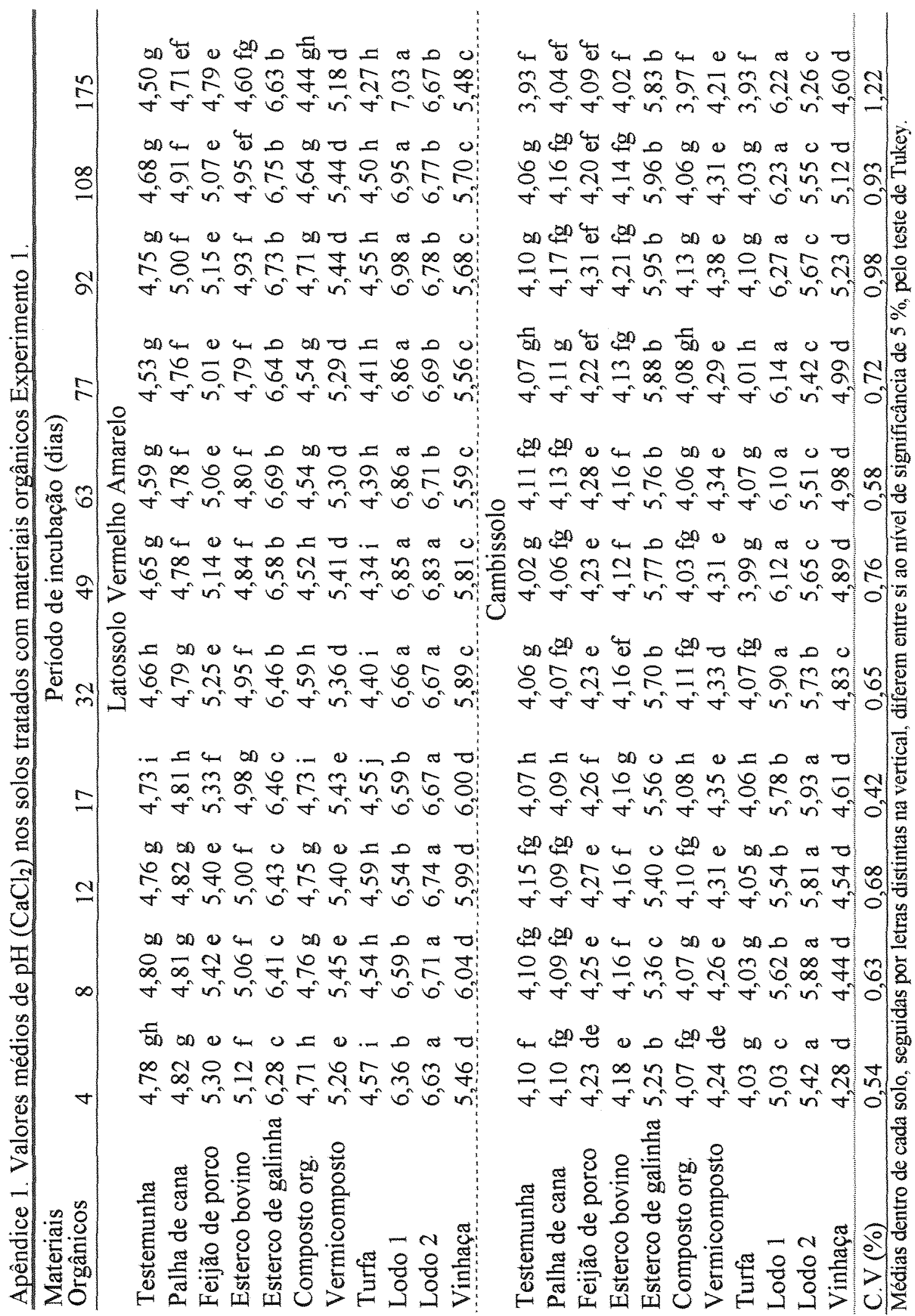




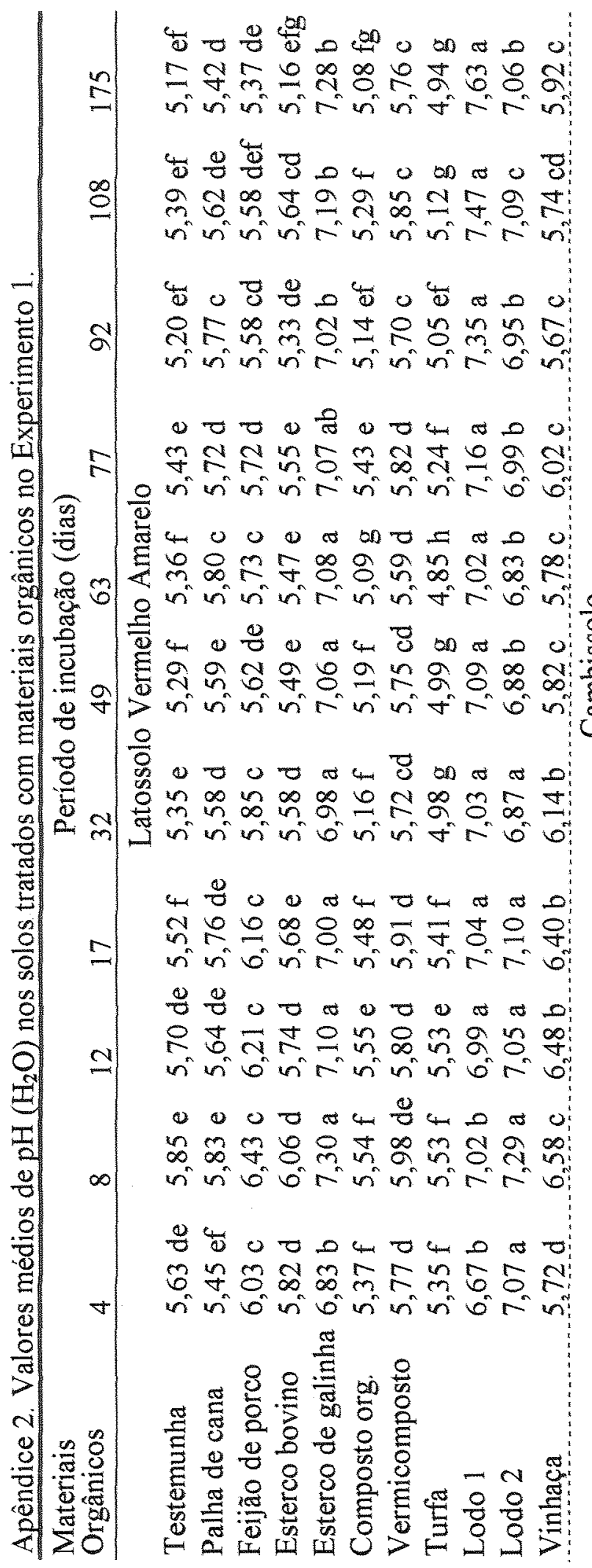

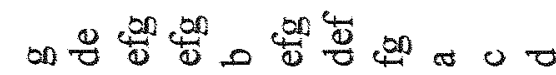

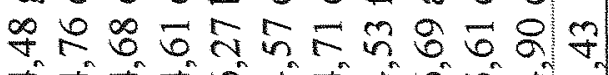
$\nabla^{n} \nabla^{n}+\nabla^{n}+\nabla^{n} \nabla^{n} \omega^{n} \nabla^{n}-$

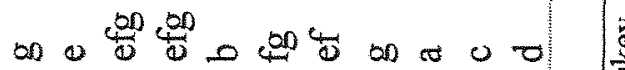
ปรँ

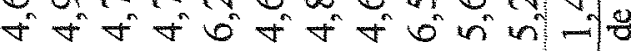

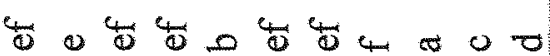

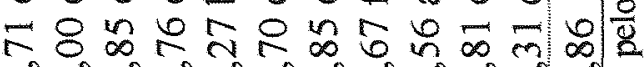

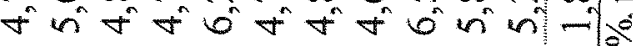

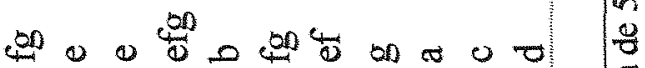

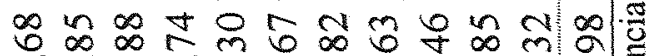

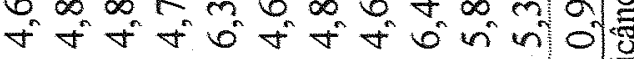
400 की $0 \frac{5}{000}=00$

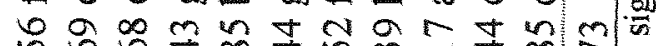

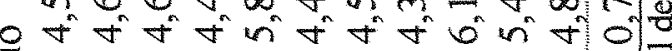
808000000000

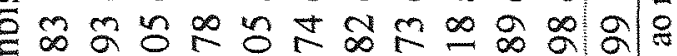
$\nabla^{n} t^{n} n^{n} \nabla^{n} \sigma^{n} t^{n}+0^{n} n^{n} \nabla^{n} 0$ ช

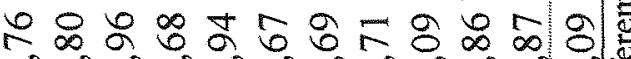

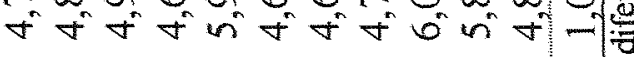

$\begin{array}{llllllllll}0 & 0 & 0 & 0 & 0 & 0 & 0 & \pi & 0 & 0\end{array}$

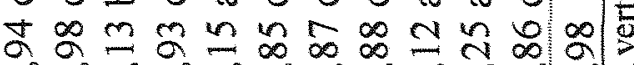
t

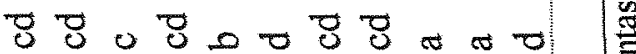
ఫ $\nabla^{n} \nabla^{n} \nabla^{n} n^{n} \nabla^{n} \nabla^{n} 0^{n} b^{n} \nabla^{n}-$

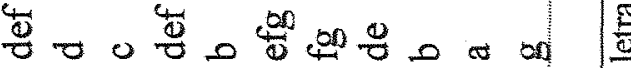

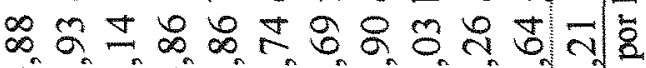
$\nabla^{n} \nabla^{n} n^{n} \nabla^{n} \dot{\pi}^{n} \nabla^{n} \nabla^{n} 0^{n} b^{n} \nabla^{n}-n$

- \begin{tabular}{llllllllll}
\hline & 0 & 0 & 0 & 0 & 0 & 0 & 0 & 0 & 0
\end{tabular} ஈ

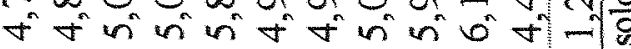

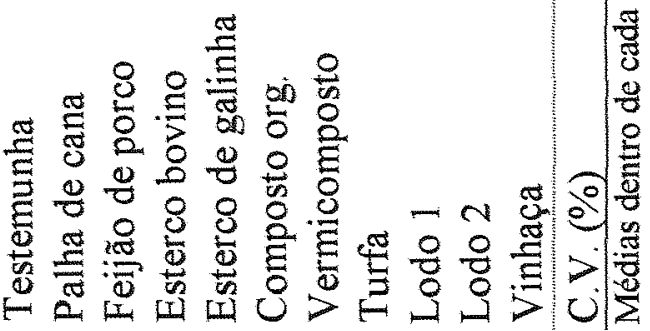




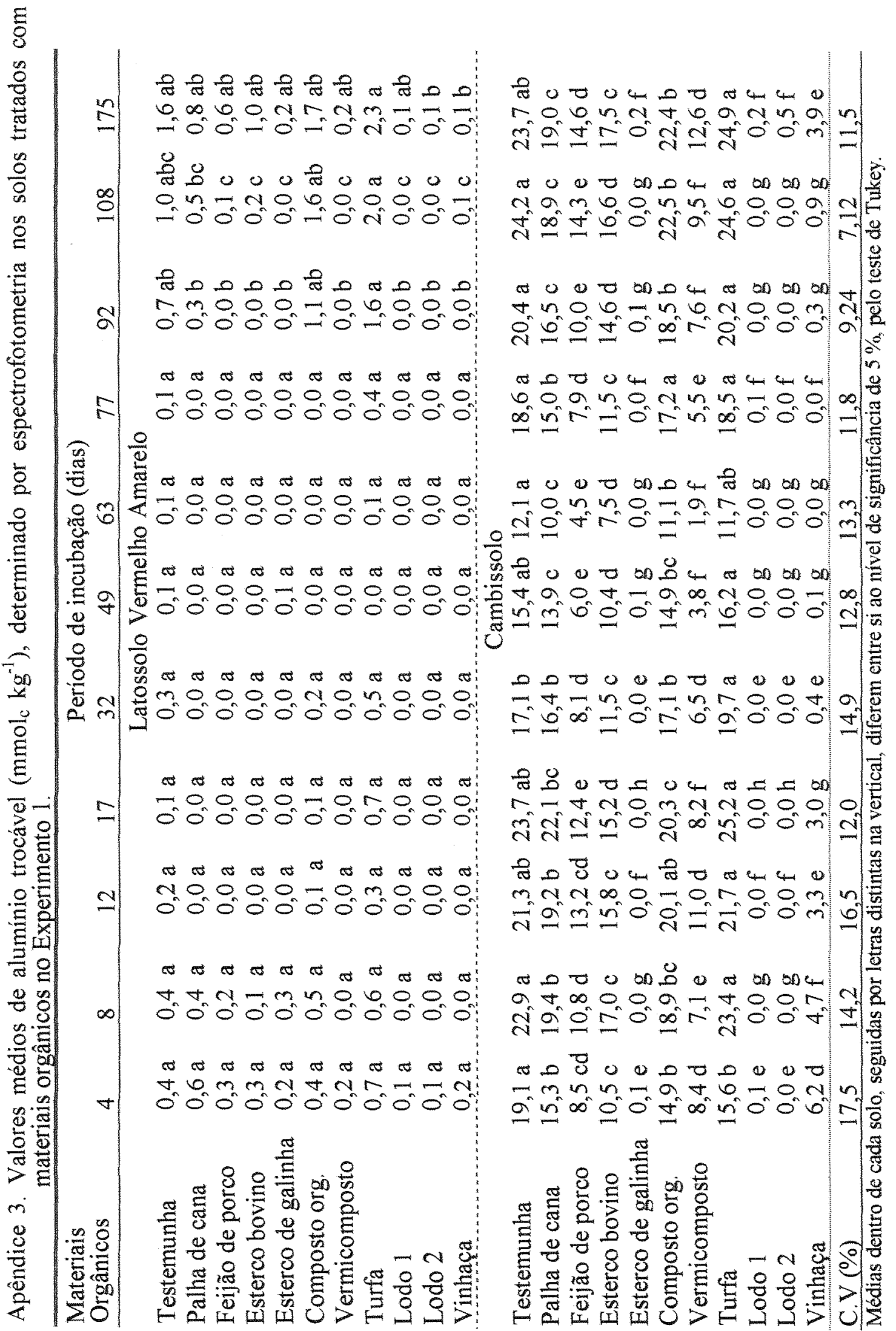


Apêndice 4. Valores médios de $\mathrm{pH}\left(\mathrm{CaCl}_{2}\right)$ do solo em resposta a incubação de materiais orgânicos no Experimento 2.

\begin{tabular}{|c|c|c|c|c|c|c|c|}
\hline \multirow{2}{*}{$\begin{array}{c}\text { Dias } \\
\text { de } \\
\text { incubação }\end{array}$} & \multirow[b]{2}{*}{ Temp. } & \multicolumn{6}{|c|}{ Materiais orgânicos -n-n- } \\
\hline & & Testemunha & $\begin{array}{c}\text { Feijão de } \\
\text { porco }\end{array}$ & $\begin{array}{l}\text { Esterco } \\
\text { bovino }\end{array}$ & Vinhaça & Lodo 1 & Turfa \\
\hline \multirow{2}{*}{0,5} & $20^{\circ} \mathrm{C}$ & 4,16 a $\mathrm{CD}$ & 4,27 a $\mathrm{B}$ & 4,24 b BC & 4,23 b BC & 5,35 a $A$ & $4,11 \mathrm{~b} \mathrm{D}$ \\
\hline & $30^{\circ} \mathrm{C}$ & 4,19 a $\mathrm{CD}$ & 4,31 a $B$ & 4,28 a BC & 4,27 a $\mathrm{BC}$ & 5,46 b A & 4,13 a $\mathrm{D}$ \\
\hline \multirow{2}{*}{1,0} & $20^{\circ} \mathrm{C}$ & 4,17 a C & 4,32 a $\mathrm{B}$ & 4,25 a B & 4,25 a $\mathrm{B}$ & $5,70 \mathrm{bA}$ & 4,12 a C \\
\hline & $30^{\circ} \mathrm{C}$ & 4,20 a $C$ & 4,35 a $\mathrm{B}$ & 4,29 a $\mathrm{B}$ & 4,28 a B & 5,85 a $A$ & 4,16 a $C$ \\
\hline \multirow{2}{*}{3,8} & $20^{\circ} \mathrm{C}$ & 4,23 a $C D$ & 4,40 a $\mathrm{B}$ & 4,33 a BC & 4,35 b BC & $5,53 \mathrm{bA}$ & 4,19 a $\mathrm{D}$ \\
\hline & $30^{\circ} \mathrm{C}$ & 4,25 a $C$ & 4,44 a $\mathrm{B}$ & 4,34 a $B C$ & 4,45 a B & 5,75 a $\mathrm{A}$ & 4,22 a C \\
\hline \multirow{2}{*}{7,6} & $20^{\circ} \mathrm{C}$ & 4,24 a $\mathrm{DE}$ & 4,42 a C & 4,32 a $C D$ & 4,78 b B & $5,69 \mathrm{bA}$ & 4,21 a $\mathrm{E}$ \\
\hline & $30^{\circ} \mathrm{C}$ & 4,23 a D & 4,42 a C & 4,33 a $\mathrm{CD}$ & 4,86 a B & 5,85 a $A$ & 4,28 a D \\
\hline \multirow{2}{*}{10,5} & $20^{\circ} \mathrm{C}$ & 4,26 a D & 4,43 a $C$ & 4,34 a $C D$ & $4,88 \mathrm{~b} \mathrm{~B}$ & 5,92 b A & 4,23 a D \\
\hline & $30^{\circ} \mathrm{C}$ & 4,27 a D & 4,46 a C & 4,35 a $C D$ & 4,96 a B & 6,10 a $A$ & 4,24 a D \\
\hline \multirow{2}{*}{17,5} & $20^{\circ} \mathrm{C}$ & 4,21 a E & 4,44 a C & 4,31 a $\mathbf{D}$ & 4,96 b B & $6,19 \mathrm{bA}$ & 4,20 a $E$ \\
\hline & $30^{\circ} \mathrm{C}$ & 4,23 a $E$ & 4,43 a C & 4,33 a D & 5,21 a B & 6,27 a $A$ & 4,20 a $E$ \\
\hline \multirow{2}{*}{25,5} & $20^{\circ} \mathrm{C}$ & 4,24 a D & 4,48 a C & 4,36 a $C$ & 5,03 a B & 6,02 a $A$ & 4,23 a D \\
\hline & $30^{\circ} \mathrm{C}$ & 4,22 a D & 4,41 a $C$ & 4,33 a $C$ & 5,16 a B & 6,06 a $A$ & 4,19 a $\mathrm{D}$ \\
\hline \multirow{2}{*}{38,5} & $20^{\circ} \mathrm{C}$ & 4,17 a $E$ & 4,38 a C & 4,26 a D & 5,11 b B & 6,18 a $A$ & 4,15 a $\mathrm{E}$ \\
\hline & $30^{\circ} \mathrm{C}$ & 4,17 a $E$ & $4,30 \mathrm{bC}$ & 4,23 a D & 5,32 a $\mathrm{B}$ & 6,19 a $A$ & 4,17 a $\mathrm{E}$ \\
\hline \multirow{2}{*}{50,6} & $20^{\circ} \mathrm{C}$ & 4,17 a $\mathrm{D}$ & 4,31 a C & 4,21 a D & 5,27 a B & 6,12 a $A$ & 4,13 a $E$ \\
\hline & $30^{\circ} \mathrm{C}$ & 4,17 a $\mathrm{D}$ & 4,30 a C & 4,21 a D & 5,28 a B & 6,10 a $A$ & 4,08 a $E$ \\
\hline \multirow[t]{2}{*}{71,5} & $20^{\circ} \mathrm{C}$ & 4,08 a $E$ & 4,26 a C & 4,13 a D & $5,22 \mathrm{~b} \mathrm{~B}$ & $6,41 \mathrm{bA}$ & 4,04 a $\mathrm{E}$ \\
\hline & $30^{\circ} \mathrm{C}$ & 4,04 a $\mathrm{D}$ & $4,20 \mathrm{bC}$ & $4,06 \mathrm{bD}$ & 5,28 a $\mathrm{B}$ & 6,20 a $A$ & $3,98 \mathrm{bE}$ \\
\hline
\end{tabular}

Dentro de cada linha horizontal, médias seguidas por letras maiúsculas distintas diferem entre si ao nível de $5 \%$ de probabilidade.

Dentro de cada época de amostragem, médias seguidas por letras minúsculas distintas na vertical diferem entre si ao nível de $5 \%$ de probabilidade. 